\title{
PHOENIX: REBIRTH OF THE FASHION IMAGE
}

By

Chloé Wilson, Bachelor of Arts, Dalhousie University 2008

\author{
A major research paper \\ presented to Ryerson University \\ in partial fulfillment of the \\ requirements for the degree of \\ Master of Arts \\ in the Program of \\ Fashion
}

Toronto, Ontario, Canada 2013

(C) Chloé Wilson 2013 


\section{AUTHOR'S DECLARATION FOR ELECTRONIC SUBMISSION OF A MRP}

I hereby declare that I am the sole author of this MRP. This is a true copy of the MRP, including any required final revisions.

I authorize Ryerson University to lend this MRP to other institutions or individuals for the purpose of scholarly research

I further authorize Ryerson University to reproduce this MRP by photocopying or by other means, in total or in part, at the request of other institutions or individuals for the purpose of scholarly research.

I understand that my MRP may be made electronically available to the public. 
Phoenix: Rebirth of the Fashion Image, Master of Arts 2012, Chloé Wilson, Fashion, Ryerson University

\begin{abstract}
The objective of this practice-based master's research project is to explore how theory on photography, communication, and mythology can be illustrated by the format, layout, and design of a 120 page alternative fashion publication in such a way that it provides insight into the relationship between mythology and the fashion image and an alternative perspective on the fashion image that goes beyond profit-driven motives. This project explores methods of collaboration and creativity by appropriating various works, personal projects, and those of contributors and collecting them into one context: the Phoenix publication. The methods of appropriation, détournement, meta, and corpse exquisite are used in the creation of this project in terms of individual submissions, layout, formatting, and the understanding of the publication as a whole.
\end{abstract}




\section{ACKNOWLEDGEMENTS}

I would like to thank my supervisor, Joseph Medaglia, whose supervision, guidance, and encouragement played a vital role in the success of this project. Thank you to Professor Alice Chu for her input and interest in my creative process. Thank you to my parents for their unconditional support and patience. I would like to dedicate this project to my father. His encouragement in the development of this project has been invaluable. 


\section{TABLE OF CONTENTS}

Abstract..................................................................... ii

Acknowledgements................................................. iv

List of Appendices...................................................vi

Chapter One: Introduction................................................... 1

Key Terms.................................................2

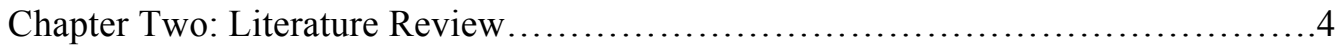

Chapter Three: Theoretical Framework............................................11

Chapter Four: Methodology ............................................. 15

Part 1: Overall Methods....................................................15

Part 2: Specific Methods...........................................18

Chapter Five: Analysis and Discussion....................................21

Part 1: Appropriation and Détournement in Creation.........................21

Part 2: Practice-Based Research: The Interrelationship Between Content, Layout, Format, Themes and Theory............................23

Part 3: The "Rebirth" Perception of the Fashion Image: The Concept of Phoenix and its Relationship Between Theory and Format............24

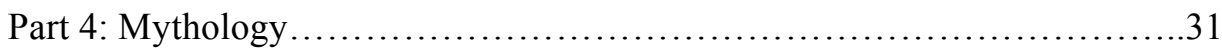

Part 5: Recurring Triadic Relationship..................................34

Part 6: Limitations................................................. 36

Part 7: Areas for Further Development.................................37

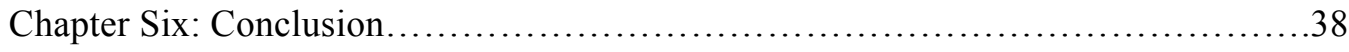

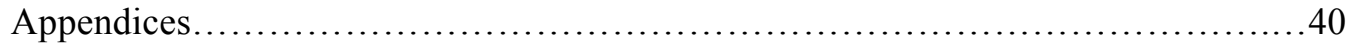

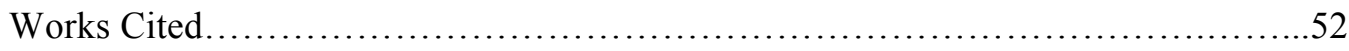




\section{LIST OF APPENDICES}

Appendix 1: Letter of consent for Ryerson's Research Ethics Board $\ldots \ldots \ldots \ldots \ldots \ldots \ldots \ldots \ldots \ldots . .40$

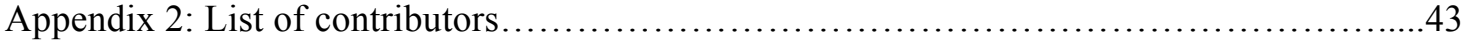

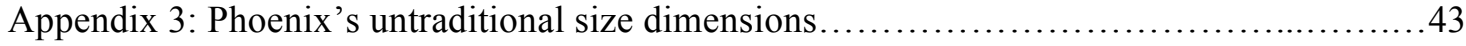

Appendix 4: The method of 'corpse exquisite' used in a specific submission..................44

Appendix 5: Appropriation Art in a specific submission...............................44

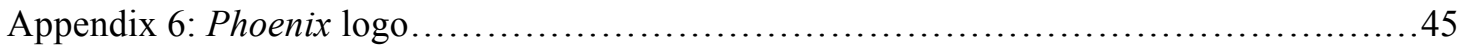

Appendix 7: The representation of a full stroke: cover image, introductory image and concluding image................................................ 45

Appendix 8: Transitory Photographs for Time Dimensions..............................46

Appendix 9: Transparent Pages for Time Dimensions.................................47

Appendix 10: Last page of Phoenix ............................................... 48

Appendix 11: Introduction to Time.............................................48

Appendix 12: Coloured paper and glossy paper used for interviews......................49

Appendix 13: Format of cutting the pages for submission "Competing in a Man's World: The Women's Shoulder Pad of the 1980s".......................49

Appendix 14: The method of 'meta' explored in the submission 'Photographs of Photographs: 1980s Fashion Advertisements in the Museum"................50

Appendix 15: Formatting of submission on "The Precession of Simulacra"

Appendix 16: Voyeurism explored through the formatting of submission "The Power of the Fashion Image: Helmut Newton and the Female Gender Identity of the 1980 s" 


\section{Chapter 1: INTRODUCTION}

Phoenix: Rebirth of the Fashion Image is a practice-based research project that creates an alternative medium to present and consider the fashion image as something more than for the purpose of generating a profit. The aim and objective of this practice-based master's research project is to explore how theories on photography, communication, and mythology can be illustrated in the format, layout, and design of an art project in such a way that it provides insight into the relationship between mythology and the fashion image, and provides a perspective that goes beyond profit-driven motives. The concept, content, format, and physicality of Phoenix have been designed with this in mind. Phoenix is a collection of 120 pages including images and written work; it is untraditional in terms of content and in terms of material form. Phoenix is 7 by 10 inches, printed in black and white on uncoated coloured and transparent paper, and printed in colour on coated glossy paper. Some of the pages are cut by hand, altering the shape of the page and emphasizing each copy of Phoenix as being one of a kind. Phoenix is self-made with limited editions.

Phoenix appropriates my work and the work of other contributors in a new context with untraditional formatting to provide a rebirth perspective of the fashion image. Phoenix appropriates in multiple ways and from different context, methods, and media. The primary technique is to appropriate what exists in mainstream fashion magazines (fashion photographs, editorials, articles, interviews, symbols, themes) and to place what has been appropriated in an untraditional format. In this way, Phoenix is a form of détournement, turning the original intent of the mainstream fashion magazine, or detouring it, as an act of criticism.

In the fashion industry, narratives (mythologies) are created and communicated by fashion images featured in mainstream fashion magazines, mostly through editorials and advertisements. These mythologies attribute meaning to a brand or product. They often include iconic female figures (models, actresses, or celebrities) who communicate illusory standards about what it means to be beautiful, feminine, sexually attractive, elite, and successful. These ideals are 
communicated to the viewer, through symbols and signs, for the purpose of increasing consumption. The danger in fashion images is that the mythologies might appear 'real' to the viewer because the medium of photography is typically associated with recording reality. Today the creation of mythologies in the fashion industry use images of highly realistic, staged scenarios that are easily manipulated with digital tools like Photoshop. When viewers associate mythology in the fashion image with truth and reality, they might attempt to emulate something that is not real (simulacra). This becomes problematic when the creation of these mythologies for profit driven motives do not weigh the negative costs of the promotion of false realities.

Phoenix incorporates a notion of timelessness. The content of Phoenix is broken up into three parts: past, present, and future. The content is categorized within these three time dimensions. The fashion industry is always looking to what is next, the newest trend, the newest style, and the next best thing. Phoenix challenges this notion of disposable, forward thinking, and instead focuses on the fashion image being cyclical. The recurrent nature of the fashion image is expressed through the content of the publication, through its circular logo, and through its name. The phoenix is a mythological bird that is a symbol of immortality. The phoenix brands this publication as a symbol for the persistence of fashion as a form of expression and having the ability to exist in different formats with different meanings.

\section{Key terms}

Mythology: a collection of myths (widely held, but false beliefs/ideas/stories) belonging to a particular culture found in different areas of cultural phenomena.

Fanzine: a publication typically produced by amateurs (non-professional, non-official) for fans of a particular or shared interest.

Mainstream Fashion Magazines: Accessible fashion magazines that share similar attitudes and ideas on fashion. The content of such magazines are in accordance with convention. Mainstream fashion magazines share similar content (on fashion, beauty, celebrity news, advertisements) and format ( 8.5 " by 11 , colour, glossy images).

Profit-driven motives: A cause, or doing something for (to benefit) financial gain. 
False ideals: A principle or value that exists in the imagination that one actively pursues as a goal; principles or values that are created through areas of popular culture (for example mainstream fashion images) that are not according with truth, fact, or reality. False ideals often imitate something in order to deceive.

Appropriation: The action of taking something; the artistic practice or technique of reworking images from other works into one's own work/reworking of others.

Simulate: To imitate the appearance or character of; pretend to have/copied; simulacrum is an image or representation of someone or something. 


\section{Chapter 2: LITERATURE REVIEW}

Phoenix explores how the value of print, cultural communication, mythology, and feminism relate to the fashion image. These themes of interest act as the building blocks for the content of my creative project. Each submission in Phoenix speaks to one or more of these themes of interest and responds to the writings referred to below.

\section{Mythology and the Fashion Image}

The mythologies in the world of fashion are created and communicated largely through the fashion image that appears in mainstream fashion magazines. The primary medium of this communication is the photograph. The fashion image is a powerful tool in contributing to ideals of female identity, femininity, and sexuality. An overview of the relationship between identity and the history of photography is found in the article Digital Photography: Communication, Identity, Memory by José Van Dijck. In the article, Van Dijck demonstrates that photographs may be a form of art, or saved as an act of memory; however, he suggests that with the rise of more technological advances, the photograph now has greater power to become a tool for identity formation and communication (58). The article refers to personal photography; however, it can be extended to the fashion image. Van Dijck looks at the digitization of photography and its effects on the purpose and use of photography.

The mythologies in the fashion industry are a product of profit-driven motives; fashion images create aspirations for people, persuading them to buy products. The aesthetics of mainstream fashion magazines are contrived in that they are not created as art to evoke emotion and critical thought, but rather to encourage consumerism. In Ellen McCraken's Decoding Women's Magazines, she examines the contradictory semiotic structure of the fashion magazine, with a focus on the construction of identity through the mainstream fashion image found in advertisements and editorials (280). McCraken demonstrates that fashion magazines are less concerned with a promotion of aesthetic and are driven more by the commitment to making profits. She describes the fashion system as a multi-million dollar industry and demonstrates how 
this industry falsifies the consensus of identity as a strategy to increase desire in the consumer (McCraken 1). Brian Moeran, in his article More Than Just a Fashion Magazine, looks at the logistics of mainstream magazines focusing on how they are constructed and developed (from designers, editors, stylists, photographers, models, celebrities, etc.); how fashion magazines fabricate myth (referred to by Moeran as 'legend-making') (739); and how the fashion magazine is founded as an economic commodity with the symbolic exchange of meaning from fashion magazines to the consumer being focused around economic exchange and profit (728). Jennifer Craik explores the fashion system from a cultural perspective in The Face of Fashion: cultural studies in fashion. Craik reviewed the role of the fashion magazine with a particular focus on the economic forces at play, describing the fashion industry as a capitalist system of production, distribution, and consumption (6). Her cultural studies of fashion in the Western modern world provide an understanding of why the fashion image is manipulated for the sake of consumerism. Each of these authors has examined mainstream fashion magazines from different perspectives and has concluded that their dominant goal is economic.

The fashion photographic image does not act as memory or capture a moment in time, since it is often stylized and contrived. The viewer may understand the fashion image as a captured moment when actually it is planned out with the intent to evoke excitements and insecurities, which in turn increases sales of the magazine, brand, designer, or product. The idealized images created for this purpose promote a sense of perfection. The imagery and lifestyle promoted in these advertisements are unattainable for most consumers. In Creating American Mythology: A Comparison of Branding Strategies in Three Fashion Firms, Veronica Manlow considered the fashion image by studying three brands: Polo Ralph Lauren, Tommy Hilfiger, and American Apparel. Manlow suggests that the linking of mythology to a brand provides leverage by associating the brand with objects that in turn create new meanings. She demonstrates this idea with the example of Polo Ralph Lauren who creates mythologies of elitism and wealth to link its product with attributes and ideals that the brand stands for (Manlow 89). 
More recently another type of false branding has emerged. In her article Diffusion Models and Fashion: A Reassessment, Diana Crane examines and explains changes in how fashion is diffused. Changes in consumption patterns and mass media increases have led to trends, styles, and fashion emerging from style tribes, street-style culture, and younger markets (15). In turn, the fashion image has evolved; brands and designers are defining their 'links' to current trends in society, as for example street-style culture. Brands and designers are no longer primarily wedded to elitist mythology branding; however, they represent mythologies that appear attainable but actually remain unattainable. This form of mythology can be even more deceptive. Though women are often the representative or "face" of a fashion brand and have gained further ownership and control over the fashion business, the fashion system remains a powerful and often negative force in the construction of women's identities. Many women continue to struggle with notions of self-worth, self-esteem, and self-identity, comparing themselves with the women on the pages of mainstream fashion magazines. The fashion image is influential and powerful in revising notions of beauty. The viewer attempts to emulate the Photoshopped, contrived, and perfected images and, in turn, women become simulacra themselves: representations of something that never existed. The power to manipulate serves the interests of those who create the mythologies. The beauty myth promoted by the fashion industry is an ideology that compels insecure consumerism. Women are constantly reaching to achieve unattainable goals from body image to keeping up with fashionable trends to looking youthful. The body, dress, and fashion reveal much about gender and sexual politics. Karen De Perthuis in The Synthetic Ideal: the Fashion Model and Photographic Manipulation, focused specifically on the body and manipulation in the fashion image. De Perthuis states that with the use of digital manipulation, the hyperbolic artifice appears normal and attainable however it has actually been manipulated to demonstrate the unattainable, what is beyond the reach of our corporeal world (412). This article is helpful in understanding mythology and the 'artificial', unrealistic aesthetics in the fashion image today that construct false ideals of beauty and reality. Angela McRobbie has prolifically 
studied the feminist view of the fashion industry. In The Aftermath of Feminism: Gender, Culture and Social Change, McRobbie suggests that because of the mythologies of the mainstream fashion image, "the contemporary young woman, self-reflexive and gender-aware, finds herself confined to the topographies of an unsustainable self-hood, deprived of the possibilities of feminist sociality, and deeply invested in achieving an illusory identity defined according to a rigidly enforced scale of feminine attributes" (120). In Post-Feminism and Popular Culture, McRobbie discusses the turning point in feminism of the 1990s when the movement, generally, began to focus more on the body and issues of representation (257). The shift moved away from feminist interest in centralized power blocks and more towards events and "instances of power conceptualized as flows and specific convergences and consolidations of talk, discourse, attentions" (McRobbie 256). Today cultural forms call women into being and produce them as subjects. McRobbie classifies areas of popular culture that have contributed to new representations of women, in particular the fashion magazine.

Angela McRobbie focuses on gender, youth culture, and subcultures. Her analysis of young women in cultural life establishes how young women develop in contrast to men. Her discussion in Feminism and Youth Culture of teenage fashion magazines like JACKIE, offers insight into the representation of young women, pop culture, and more specifically fashion magazines and how such representation affect the construction of female gender identity (McRobbie x). McRobbie leads this discussion into the matter of postmodernism in culture, which is discussed further in Postmodernism and Popular Culture where McRobbie examines the evolution of fashion magazines since the 1970s, identifying the consequences of cultural proliferation, specifically the mainstream women's magazine. McRobbie uses a feminist framework and a sociological perspective to analyze phenomena in mainstream women's magazines such as the unprecedented female sexuality displayed in its pages.

There have been very skilled artistic photographers working in the fashion industry. The fashion image, however, with its close association to the creation of mythologies "is traditionally 
regarded," Rosetta Brookes notes in The Double Page Spread: Helmut Newton, Guy Bourdin and Deborah Turbeville, "as the lightweight end of photographic practice. Its close relationship to the economic imperatives of turnover makes the fashion photograph the transitory image par excellence" (520). Images that promote the sale of fashion are themselves infected with the transitory nature of fashion. Phoenix strives to celebrate the images of fashion beyond profit driven motives.

\section{The Value of Print}

Mainstream fashion magazines replete with fashion imagery have availed themselves of the powers of the Internet. As the Internet exploded upon us, mainstream fashion magazines full with fashion images took advantage of the new technology. Increasingly, fashion imagery is made to be viewed online and, with the growth in online reproduction, hard copy magazine sales and production have decreased. Media theorist Wolfgang Ernst suggests that archives no longer need to contain bookshelves or libraries (Soussloff, Tronzo, and Rubin 2008). The technological changes have made it easier for the fashion industry to disseminate mythologies for the purpose of promoting consumption. Today fashion photographs are accessible to anyone and everyone, reaching a wider audience. Magazine publishers have joined the online world and now offer both virtual and hardcopy version of their magazines to subscribers.

Each of the two formats - virtual and hardcopy—are significantly different from one another, and the adoption of one involves disadvantages suffered by foregoing the other. The virtual world provides brands and designers with a format, through blogs, online magazines and e-commerce editorials, to advertise to as many people as possible. Blogs are representative of the fast-pace nature of the fashion industry in that they are ephemeral, changing daily, sometimes every hour. Images in blogs, like trends in fashion, come and go quickly creating a sense of irrelevancy. The turnover rate of what is being showcased online is fast pace, giving an image little time to be appreciated by the viewer. For people engaged in a lifelong love affair with books and their physicality, the fleeting images and reading online do not meet their needs. The 
Aesthetics of Publishing: the Art Book as Object from Print to Digital consists of a collection of papers by different authors on the aesthetics of publishing print versus digital. While all papers are in reference to the art book, these authors examine the image and its context. Specifically, Catherine M. Soussloff refers to the appealing nature of the art book as a context for images in comparison to the digital world in that the art book appeals "to our intellect through our senses, and thus to our imagination" (41). The printed images, page and text layout, page format, designed font, the material paper, and binding demonstrate the incongruity between aesthetics and digitalization (Soussloff 41).

The computer industry is still too young to make informed decisions about the archival powers of hard drives as a device to store images compared to the relative permanence of print. What is more certain is that for many people there is a distinct difference between reading and viewing images on paper compared to on monitors. In the article, I Want to Hold it in my Hands: Readers' Experiences of the Phenomenological Differences Between Women's Magazines Online and in Print, Brita Ytre-Arne studied the phenomenological differences between reading women's magazines as opposed to online magazines (blogs, websites, etc.). According to YtreArne, the experience of reading a hardcopy is much different than an online copy (468). Images in a hardcopy book or magazine engage the senses; being able to touch the tangible book and flip through the pages creates a personal gallery. The weight of the pages, whether the images are matte or glossy, satin finished or textured is a part of the visual experience missing when viewed on a monitor. When images are shown digitally it changes the interpretation of the image. For many interviewed in this article, the virtual form of reading is substantially inferior for people who engage with the material upon which the images and words are printed (Ytre-Arne 469). These are the people who appreciate how print elicits the senses; they like the touch of the pages and the smell of the paper; they appreciate the ownership of the physical book.

Gwen Allen and Cherise Smith, in their article Publishing Art: Alternative Distribution in Print, looked at the introduction of alternative print in the 1960s and 1970s and provide a 
historical perspective (41). This article demonstrates an understanding of the purpose of the alternative publication as a space of media that reveals communication structures of culture and the 'real' world (Allen and Smith 43). The authors explain how the alternative magazine was seen as an alternative distribution of art not only because of its content but also because of its physicality (42). This article discusses the importance of the physicality of print in terms of layout, materials, and format. The fanzine opposes dominant ideologies and consequently its physical format opposes the traditional magazine format. The fanzine has generally been understood as a product of a subculture, produced by fans of a certain cultural phenomenon. Media theorist Dick Hebdige is known for his work on subcultures. In Subculture: The Meaning of Style, Hebdige defines subculture, generally, as a group that challenges tradition and disassociates with the norm or context of mass culture. In Hiding the Light, Hebdige looked at how images are created and consumed today and he reviews the power of the image in popular culture (94). Though not always specific to fashion, Hebdige's ideas in Hiding the Light aid in understanding the role of fashion in today's world and fashion's relationship to art. His work on the dichotomies between fashion and fine art are relevant when considering the fashion image and its relationship to art on the one hand, and it being the product of a profit-driven motive on the other. 


\section{Chapter 3: THEORETICAL FRAMEWORK}

The study of mythology provides a foundation for this project. In particular I have drawn on three aspects of mythology: how myth is established and communication through signs and symbols; the medium through which this communication takes place, the photograph; and the consequences of mythology. These components are associated with Susan Sontag who explores the medium of photography, Barthes who discusses how myth is established and communicated through signs, and Baudrillard who discusses simulacra. Together, they create a triadic foundation for understanding the role, value, and power of mythology in images. I have drawn, in particular, upon Roland Barthes' Mythologies, Susan Sontag's On Photography and Jean Baudrillard's “The Precession of Simulacra." Their writings have provided a perspective, or lens, through which to create and reflect on my creative project. This theoretical framework specifies which key variables influence the phenomenon of the fashion image, in turn informing my creative project (as a whole and its content).

In his seminal book, Mythologies, Barthes draws upon Ferdinand de Saussure's system of meaning through signs to explore modern myths and how they are created in society. His analysis of myth can be applied to the fashion image today. His theories are helpful for understanding the creation of mythologies and how they are communicated to the viewer. Barthes identified economics as the underlying reason for the prose of fashion in fashion magazines, and in a similar way I submit that economics and, in particular, profit driven motives are the underlying reason for mythologies in the fashion images found in mainstream fashion magazines. In Barthes' later book, The Fashion System, he identifies the mythic dimensions of fashion; Phoenix serves to challenge such dimensions.

Mythologies is separated into two sections:

i. Mythologies

ii. Myth Today 
In the first section, "Mythologies," Barthes provides various examples where myth exists in modern society. In the second section, "Myth Today," Barthes goes further by applying the study of signs, symbols and semiotics to discuss the significance and communication of mythology. Barthes borrows Ferdinand de Saussure's dualistic notion of signs: 'the signifier and the signified,' where the signifier is the form of the word while the signifier is the mental concept. The theory of signified and signifier can be directly applied to the fashion image according to which the mythology perpetuates current ideologies; it is a tool used in the fashion image to sell products, brands, designers, etc. Consider for example a Louis Vuitton advertisement in Vogue. The signifier (product) is a leather handbag. The handbag does not symbolize more than what it is. The signified includes the supermodel wearing a fur jacket, diamond necklace and ring in a luxurious setting. The combination of signifier and signified symbolize and perpetuate the myth of elitism, success, and beauty.

Barthes discusses how mythologies often allow socially constructed notions to become common and accepted. The fashion image creates mythologies about desired goals and perpetuates those notions. This applies to the effects of how and why mythologies are communicated through the fashion image. Barthes' theory was published in 1957 and remains relevant today, particularly with regards to the fashion system. Barthes' insights are very in line with Marxist theory as he touches on how mythology is created by bourgeoisie society to create aspirations for those of lower classes, in turn maintaining a status quo. It is the fashion image in mainstream magazines that also serves the purpose for designers and their brands to further their profit-driven motives.

In On Photography Sontag writes about the role of photography in capitalist societies from the 1970s. Her historical account of the idealistic and aesthetic notions of photography can be applied to the creation the fashion image. Her theory and analysis of the medium of photography provides insight into the role of photography as the principal medium of the mainstream fashion image. Today we live in an image-obsessed society. The proliferation of 
photographs in modern society underscores the importance of considering the relationship between the photographic image and reality and our understanding (as viewers) of this relationship. Sontag viewed photography as being connected with a discontinuous way of seeing; she considered photographs as fragments of reality, as a window to truth, as a framed moment, and equated photography with sexual voyeurism: the Phoenix publication reflects these ideas.

The "The Precession of Simulacra" by Baudrillard offers a philosophical discourse on the relation between reality, symbols and society. Baudrillard discusses representation and the substance (or quality) of the original. He largely considers political thought, capitalism, and nuclear proliferation, but the ideas developed apply to the fashion system and more specifically the fashion image. Baudrillard argues that a simulacrum is not a copy of the real, but becomes truth in its own right: the hyperreal. By way of example we see this with religious iconography. When we think about the concept of the hyperreal in relation to the fashion image, one can see parallels to Sontag's work. Sontag argues that such images "are indeed able to usurp reality because first of all a photograph is an interpretation of the real" (154).

Baudrillard's theory asserts that simulacra are perceived as negative because reality becomes unrelated to how we understand our lives. This too can be further exemplified with the use of simulacra in the fashion image. Consider a street style fashion shoot that pretends to capture a random moment. However, nothing in the image is random and after the application of Photoshop and other tools of manipulation, much of the image becomes unrelated to reality. As the consumer aspires to these images, his or her reality tends to the unreality of the image.

Baudrillard argues that postmodernity is an era organized around simulation. This is very much the case with the mainstream fashion image. Mainstream fashion images are ripe with mythologies, mainly for the purpose of selling a brand, product, or designer. False ideals are communicated to the viewer who often will be unable to reach these unattainable ideals (because these ideals are not 'real'). In turn, simulations replace reality. Power is created through signs and models found in the constant bombardment of hyperreal images. 
Baudrillard emphasizes that the simulacrum becomes the model for what is real. In turn, the simulacrum confuses the viewer's notion of what is real. The viewer attempts to emulate the Photoshopped, contrived, and perfected images. The power of the simulacrum, in this sense, demonstrates how the image has the power to be a part of "sorcery and evil" (Baudrillard 456). In terms of the fashion image, mythology and simulacrum are synonymous; both are used as tools to encourage consumerism, entangled in the process of selling a product, a look, trend, style, brand, or designer. The power of the mythology and simulacrum of the mainstream fashion image commodifies domains of social life and affects our notions of identity, self-worth, and selfesteem. "The primitive notion of the efficacy of images presumes that images possess the qualities of real things, but our inclination is to attribute to real things the qualities of an image" (Sontag 158). This inclination to interpret an image as capturing a moment empowers the fashion image and makes the mainstream fashion image an incomparable force for deciphering and predicting behaviour.

Together, the works of three theorists, Sontag, Barthes, and Baudrillard provide a collection of concepts and ideas that become interrelated when applied to the fashion image. This theoretical framework guided my research, informed my research questions, and played an important role in the development of my creative project: Phoenix, the publication. Much of the content, from personal projects to those of contributors, as well as the formatting of the publication can be analyzed and explained through the perspective of my theoretical framework. It is this theoretical framework that guided me through this exploratory study of the fashion image. 


\section{Chapter 4: METHODOLOGY}

\section{Overall Methods}

\section{Practice-Based Research}

The methodology used in this master's research project is practice-based as it involves the production of a creative project informed by theory and research. The creative project, Phoenix, demonstrates how creation, research, theory, and the interpretation of the completed publication interact to provide new knowledge and insight into the fashion image. In "Knowing Through Making: The Role of the Artifact in Practice-Led Research," Maarit Makela explains how a creative project, the process of creation and the final artifact, can be a way of conducting research. The role of Phoenix in this practice-based research project is to explore and engage my theoretical framework through the individual submissions (which speak to one or more of my themes of interest) and through the publication as a whole, acting as a response to current literature. The current literature recognizes the negative aspects of fashion images in general but provides no positive answer to this criticism; Phoenix fills that gap. Through format, content, and methods used in creation, Phoenix translates my theoretical framework into a creative work of art. Interpreting the theoretical framework in reference to the design process will give a voice to my creative project and, as stated by Makela, "forms a new, creative way of doing research" (157). By placing the creative project in this theoretical context, my publication acts as a creative, visual engagement of the knowledge embodied in such theories applied to the fashion image.

It is through reflecting on and interpreting the synthesis of theory and practice in Phoenix (as a whole, and through its parts) that new knowledge on the fashion image is presented. The content and the format of Phoenix respond to each other, and this synthesis of theory and practice adds to the body of knowledge about the fashion image. Makela explains that in practice-led research, the making and reflecting on the creative component are essential in research (157). This master's research project uses the creative practice as a means to conduct research. The 
creative practice when combined with theory generates a new point of view on doing research and more specifically a new perspective on the fashion image.

\section{Collaboration and Creativity}

The value of collaboration in creativity for this project leads the development of various perspectives and ideas. Most research emphasizes individual creativity, but more recently, as seen with works such as Group Creativity: Innovation Through Collaboration by Paul Paulus and Bernard Nijstad, there has been an increased awareness of the benefits and importance of the social factors in collaborative creativity. The development of innovation in creativity can be enhanced from collaboration. That said, collaboration acts as a method used in the creation of Phoenix.

Hierarchy and exclusivity rule the fashion industry, particularly when it comes to mainstream fashion magazines. Fashion images in mainstream fashion magazines are created by highly regarded art directors and photographers who are often confined to the boundaries of their commissioner; they are created for the purpose of advertising, which in turn serves the goal of increasing profits or sales. Parallel and in contrast to the images in mainstream fashion magazines, there are unknown artists who weave their pictorial images and narratives of fashion from their imagination. Their fashion images are not advertisements created to sell a product or brand but rather were conceived to celebrate fashion as an expression of creativity and culture. Such works are not created to be showcased in the mainstream fashion magazine (because they are not advertisements). Submissions include the works of photographers, illustrators, graphic designers, writers, editors, filmmakers, and painters, whose divergent processes in creation and perspectives on the fashion image will introduce new ideas and possibilities for what constitutes a fashion image. The fashion image is democratized in three ways; the collaboration of different artists on individual submissions, the ability of other artists to create freely from the structures of the mainstream fashion magazines, and the search for expressions of opinions and creativity from others. What is common to the contributors is that their work speaks to the fashion image albeit in 
different ways. Group diversity and creative potential integrated into one project provides wider understanding and innovation. The differing media and perspectives provide an extensive alternative portrayal of the fashion image.

As stated by Nijstad and Paulus, "creativity is not an individual-level phenomenon...it (perhaps always) involves some degree of interaction" (326). The collaboration of various contributors brings knowledge, skill, and abilities together, in turn providing stimulated creativity. Collaboration and creativity is used as an approach in the making of this publication in various ways. The individual works are collected and composed together, becoming one publication, acting as one creative project: Phoenix. In this sense we see how the publication is a product of creative collaboration.

The formatting of the different submissions in Phoenix parallel this notion of the collection of works becoming one. Some submissions continue to the following page or aspects of a submission continue in another submission. This creates a sense of unity and a thread of collectivity throughout.

Creativity and collaboration are used as an approach in creating specific submissions. Methods like the Surrealist's 'corpse exquisite' explore how a piece of work is passed on from one artist to the next (which is further discussed in the specific-methods section below). It is in this way that we see an idea develop through the creative process of collaboration. The link between diversity and creativity parallels the purpose of this project: to provide a 'rebirth' perspective on the fashion image. Additionally, there are specific submissions that speak to appropriation art, which can be seen as a disconnected collaborative process: images are appropriated from existing works to create something new. Lastly, though not explicit to the process of creation, there is a relationship between the artifact, Phoenix, and the viewer/reader, which speaks to the value of cultural communication through creativity.

Collaboration and contribution are explored throughout the process of creating Phoenix. Keith Negus and Michael Pickering have written that the creative experience requires a will to 
expression and to communication (22). Phoenix exists in order to spur new ideas and inspire innovative thinking about the fashion image. In this way Phoenix acts as a social system, where different ideas, works, and opinion interact. Curated together, the works of a variety of contributors act as one, evoking emotion and critical thought from the viewer through content and format.

\section{Ryerson Ethics Board Process}

As previously mentioned, submissions include my works and those of contributors. Contributors include friends, peers, previous colleagues, and individuals in the creative fields who share an interest in the fashion image being celebrated beyond the confines of profit-driven motives. Submissions were chosen by contributors themselves and others were requested by myself (the editor). Some submissions were created solely for the purpose of Phoenix and do not exist elsewhere. Others were previously created but have been laid out and formatted in a unique way in Phoenix. Contributors were not financially compensated for their submissions. Three participants were interviewed. Each interviewee was contacted via e-mail, requesting her or his participation in the publication. A Research Ethics Consent form was attached to each e-mail. Each of these interviewees was required to indicate that she or he had read, understood, and accepted the Ryerson Ethics Board Consent form in order for the interviews to take place and be featured in Phoenix (see Appendix 1).

\section{Specific Methods}

This creative art project was guided by specific methods: corpse exquisite, détournement and meta. They shaped the content and the layout of the project. They connect theory with format and demonstrate how theory can take the form of design in the creative process.

Corpse exquisite was a product of the Surrealist movement. It is a technique by which a single work is collectively assembled by multiple contributors with each successive contributor adding to the work. Corpse exquisite is often used in collages with each contributor's work observable on its own and as a part of the whole. This multiple input promotes cultural 
communication and allows us to appreciate explicitly collaborative and collective acts of creativity.

Détournement is an act of appropriation, it "is the integration of present or past artistic productions into a construction that surpasses them" (Wark 145); it is an act of 'copying,' which in turn is created into something new, "restoring agency to the act of appropriation, rather than merely adding to the stock of worthless copies that surround us" (146). The Letterist International of the 1950s was a Paris-based collective of radical artists and theorists who used détournement to challenge expressions of the capitalist system, turning such expressions against themselves. Détournement is sometimes criticized as plagiarism but it is merely a fragment of the original, detached from its original frame of reference and context, detached in space and time. There is a link between an anti-fashion alternative publication, which challenges the mainstream publications, and détournement in that they each emphasize the destructive moment: destruction of magazines, destruction of the mainstream fashion image, destruction of an original, and destruction of the oppressive barriers of mythology and mainstream fashion.

Some of the contents of Phoenix can be considered works of appropriation, and some of the content speaks directly to appropriation artists. Phoenix includes a collection of works of others as well as my own and puts these works into a new context. These works taken together in this creative art project can be individually observed but take on a new meaning when considered together with reference to the fashion image and serve the purpose of challenging the profitdriven mythologies of the mainstream fashion image. It is this process of appropriation for the purpose of critiquing that makes Phoenix a work of détournement. This method of détournement is used to demonstrate the value of taking something familiar and giving it new meaning as a form of critical thought.

The prefix 'meta' is defined in The New Oxford Dictionary as denoting a change of position or condition; denoting a position after or beyond; denoting something of a higher or second-order kind (1162). In the development of Phoenix, meta was used as a method of creation 
and analysis. It was used to connect theory with format and layout; that is, how certain works are visually and physically displayed. Sontag has explained the photograph as a stencil of the real thing (154); meta visually points to the relationship between the image and reality and acts as a method to critique through formatting content. The method of meta in displaying these works is used as a tool to critique notions of representation and association; that is, simulacra and associations. Phoenix in its totality serves as a meta-abstraction. It includes images of images of the individual works of contributors.

Each of the specific methods used have similarities; for instance, the use of appropriation and abstraction. Both are used to take something out of its familiar context and give it new meaning, or critique its origin/context, by removing it from its associations. The purpose of this project is to understand the fashion image beyond the context of profit-driven mythology. 


\section{Chapter 5: ANALYSIS AND DISCUSSION}

\section{Appropriation and Détournement in Creation}

\section{Phoenix is a Work of Détournement and Appropriation Art:}

Phoenix is a collection of works by various contributors that have been taken out of their original context and placed together in an untraditional format. Though such works are not transformed or altered when combined in Phoenix, they are decontextualized, acting as one object: one publication. In creating Phoenix, various methods of appropriation are used in the style of photographing and in particular submissions. As a whole, this publication offers an alternative perspective on the fashion image and a re-evaluation of our current understanding of fashion imagery. In this way, Phoenix is a form of détournement, which as described above uses expressions of the capitalist system to criticize capitalism. Phoenix's challenge of mainstream fashion images is inspired by the thinking of Sontag, Barthes, and Baudrillard, each of whom looked at the world around them to draw adverse inferences about consumption. The primary technique used in Phoenix is to appropriate what exists in mainstream fashion magazines (fashion photographs, symbols, themes) and to turn it, or to detour it, to criticize itself.

\section{Appropriation in Creating an Alternative Medium:}

Phoenix takes elements of both mass-produced mainstream magazines and limited Indie production fanzines for the purpose of criticizing the mainstream magazines and in this way it provides an alternative context in which the fashion image may exist. Phoenix includes interviews, glossy images, editorials, and articles, which are all common to the mainstream fashion image. However, Phoenix is self-made and of limited edition; it is not produced for mass consumption or for reproduction. Phoenix is not created to encourage consumerism; rather it is created for people who share a common interest. Contributors are not financially compensated. Phoenix includes no advertisements and is circulated free of charge. These characteristics are common to the traditional fanzine. 


\section{The Appropriation of Contributors' Work Into a New Context:}

Phoenix is the product of my own and other contributors' works (see Appendix 2). The collaboration of various contributors, those well known and those lesser known, is commonly used in the creation of the traditional fanzine. Each submission addresses different areas of fashion while speaking to one or more of my themes of interest. Dominant among those themes is cultural communication (collaboration and creativity) in order to eliminate the boundaries of high and low art.

Barthes concluded that mythology (signs) was used as a tool for the bourgeoisie to dominate or to maintain the status quo. Phoenix serves the opposite purpose; Phoenix is a more democratic kind of fashion reading in that its contributors are not dominated by a closed group of photographers. It explores the relationship between different forms, in terms of medium and style, of expressing fashion. It is not about advertising. Phoenix communicates its intent through the articles, the images, and the alternative layout and format. Taken together the sum of these parts equates to Phoenix: a work of appropriation art.

\section{Appropriating Alternative Formatting Characteristics Common to Traditional Fanzine:}

The hands-on, limited-edition approach used in Phoenix is common in the method of traditional fanzine creation and takes advantage of the different possibilities of working with hard copy; it speaks to the value of print. At 7 by 10 inches, Phoenix has smaller dimensions than the mainstream fashion magazine that is generally 9 by 11 inches (see Appendix 3). Phoenix combines the use of various paper-types such as uncoated colour, glossy, cardstock, and transparent. Once printed, the publication is reworked by hand. Pages are cut, and images are cut and pasted on top of the page to convey ideas and theory.

\section{Methods of Appropriation Explored in Specific Content:}

Methods of appropriation are explored in the layout and format of specific submissions, in the content of specific submissions, and in the images of specific contributors. All these submissions speak to appropriation art. They specifically raise questions about the life of the 
image, originality, and authorship of a work. The fashion image is about photography, and as such Phoenix predominantly features photographs, which according to Sontag is appropriation in its own right: "the act of taking pictures is a semblance of appropriation" (24). Photography appropriates the real world, creating a duplicate (image) world. Appropriation can be understood as an abstraction of something else. This meta process is explored in Phoenix in multiple ways. The submission about Helmut Newton and the submission titled "Photographs of Photographs" demonstrate appropriation with layout and format (this is further discussed below). Other works speak directly to appropriation art. For example, the article on Richard Prince discusses the life of the image, as symbols, signs, and icons are transported from one work to the next, changing form through medium along the way. The article on graphic designer Nick Thomm discusses his style of appropriating historical icons into his images. Other works, such as those of Kathryn Macnaughton and Danielle Hession, are themselves works of appropriation. Each artist has pirated an image and made a new image, changing the meaning of the original. Kathryn Macnaughton appropriated a photograph taken by Renée Rodenkirchen. She overlaid the use of illustration and graphic design over the original photograph. Macnaughton created a hyperreal version of the image, which intensified the artifice of the image (see Appendix 4). Danielle Hession combined reproductions of iconic images from mass culture (one of Brigitte Bardot, the other of Kate Moss), and combined each photograph with different media, paint, pencil, and everyday materials like cardboard, paper, yarn, and sparkles to create a unique collage (see Appendix 5).

Practice-Based Research: The Interrelationship Between Content, Layout, Format, Themes and Theory

Each submission in Phoenix-its content, its layout, and its format-speak to one or more of the themes of interest and speak to one or more of the theories of Susan Sontag, Jean Baudrillard and Roland Barthes. There is a constant relationship throughout the publication between content and theory, content and layout, content and themes, content and time. These 
relationships are dependent on one another, building from another, like steps leading up to a larger general understanding of the fashion image. In this way, Phoenix acts as a tool, a creative instrument that measures the life and value of the fashion image beyond our current understanding of its current purpose as an implementation of profit-driven motives. My original research goal was to investigate components of the fashion image and its production to discover how they might together illustrate the fashion image separate from the goal of producing mythologies for profit. Ultimately my research goal was to investigate how theory, themes, and concepts can be translated in the format, layout, and design of an art project and how that project, Phoenix, can provide insight into the relationship between mythology and the fashion image. This project contextualizes and interprets the fashion image through the creative process, both in theory and in practice. The creative project itself, Phoenix, produces a new point of view on the fashion image, which I will now turn to.

\section{“Rebirth" Perception of the Fashion Image: The Concept of Phoenix and its Relationship Between Theory and Format}

Title:

The phoenix is a mythological bird that can live up to 1,000 years. When it dies, its body is burnt to ashes, from which a new egg arises and a new phoenix is born, continuing the line of immortality. Like the phoenix bird, my publication is meant to convey the perception of the 'rebirth' of fashion, shifting the emphasis from consumerism to artistic value. The phoenix brands this publication as a symbol for the persistence of fashion as an expression of creativity and culture.

$\underline{\log o:}$

Unlike the ephemeral fashion world to which we are accustomed, Phoenix demonstrates the fashion image as something timeless and valuable. The logo for Phoenix is a stylized and elegant circle (see Appendix 6). It symbolizes the cyclical nature of fashion and its beauty.

\section{Dimension of Time:}


The economic model in the western world is about increased sales and earnings. The business of fashion in this economic model encourages looking to what is next, the newest trend, the newest style, the next best thing. Phoenix challenges this ephemeral nature of fashion and specifically the fashion image and instead focuses on the cyclical nature of the fashion image. The content of Phoenix is divided into three parts: past, present, and future with the content categorized within these three time periods. These three sections provide a dimension of time. This dimension of time incorporated in my creative project is intended to demonstrate the timelessness of fashion, which adds to the thread of 'anti-fashion' seen throughout.

The first image in Phoenix is of a woman diving forward. This page introduces the contributors of the publication. The image symbolizes the reader diving into the publication. The last image is of the same diver's legs and feet, swimming out of the publication. The pairing of these images at the beginning and the end symbolizes the reader's journey through the publication as a full stroke. It is fitting that the cover of the publication is of that woman completing a full stroke upwards, to the surface, for a breath of air (see Appendix 7).

Content (submissions) in Relation to the Dimension of Time:

Submissions within each dimension have been categorized based on the submission's subject or style and how it relates to past, present, or future. The submissions at the end and beginning of each dimension or section act as a transitory submission that connects one time dimension to the next. The fashion image travels from past, to present, to future, and back to past. Sontag suggests that a photograph "testifies to time's relentless melt" (15), in that a photograph captures a moment in time. The works featured in Phoenix are shown in the past, present, and future to preserve the notion of time so that it does not 'melt' away.

\section{Separations of Time Dimensions:}

As mentioned above, the submissions at the end and beginning of each dimension, act as a transition from one time dimension to the next. This demonstrates how the past links to the 
present, the present links to the future, and the future links to the past. Each dimension is separated with a transparent page. This transparent page serves as Sontag's consideration of the photograph as a window onto reality; here these transparent pages act as windows on the succeeded time dimension. A transitory photograph is chosen for each separation of time. Each transitory photograph, taken by Nicolas Wilson, is broken into two halves by the transparent page. The three photographs are a series, each speaking to one dimension of time. Sontag claims "to photograph is to frame, and to frame is to exclude" (6). While driving down a highway, Nicolas Wilson takes a photograph of what is behind him, beside him, and ahead. He attempts to document the entire context; the perimeter of his vision, excluding nothing. Phoenix begins with a definition of time: " Time is the indefinite continued progress of existence and events in the past, present, and future regarded as a whole." Each photograph of this series represents a time dimension but is considered one series, a whole (see Appendix 8).

This series of photographs by Nicolas Wilson are mythological, but not for the purpose of promoting false ideals. The series attempts to document moments in a journey on the highway at night. Each photograph captures an unplanned moment, an experience captured. In this light, they are documentary photos; however, because of the lights and movement of the cars, the subject matter is distorted. The distortion creates an illusory effect and forces the viewer to question what is being photographed. Though not necessarily intended, the photographs become abstract, surreal, and mythological. "Photographs which cannot themselves explain anything are inexhaustible invitations to deduction, speculation and fantasy" (23). It is this form of mythology that is fascinating in photography. The images in Phoenix use mythology to incite reverie, thought, and emotion rather than to create false ideals and encourage consumption.

Fragments of the Phoenix logo are placed on the separating transparent sheets of each time dimension. Past features the left side of the logo, reaching backwards to what is behind us. The transparent paper is black. All that is transparent is the slice of the logo. All that we know of the past is in between the lines, the specifics, and facts. Present is the top of the circle logo, 
acting as a bridge between yesterday and tomorrow. The page is almost completely translucent, the present is clear because we are in it; we observe and live it. Future is the right side of the logo, reaching forward to what is next. The page is transparent other than the portion of the logo, suggesting that we can infer what the future holds generally, but facts remain unclear as they have not yet occurred (see Appendix 9). At the end of the publication, miniature images of each submission are layered on top of one another, with the full Phoenix logo, as a whole, placed on top. The arrangement symbolizes the content as a whole representing one full circle of time, one original, a whole (see Appendix 10).

The fragments of the logo demonstrate that each dimension of past, present, and future is merely a fragment of the whole. This pays homage to Sontag's notion of a photograph being a fragment of reality, not statements of the world, but more pieces of it: miniatures of reality. Sontag compares a photograph to a quotation from a book, merely a slice, or a fragment of the whole. Sontag states that the ultimate wisdom of photography is that a photograph provides the surface and invites the viewer to think and feel what is beyond it (71). Phoenix mirrors this invitation with relation to our understanding of the fashion image. This concept of photography acting as fragments of truth is demonstrated throughout the publication with its format and content. The transparent pages reflect Sontag's theory that the photograph is a window into reality. The cut pages in Phoenix represent the theory that the photograph acts as a portion or fragment of the truth. Additionally the fragments of the logo speak to the dimension of time, acting as portions of a whole.

The publication begins with a transparent page with the full Phoenix logo printed in black. It says, "Time is the indefinite continued progress of existence and events...," and continues on the backside, “...in the past, present, and future regarded as a whole.” This represents Phoenix's philosophy of time, something that is indefinite; the fashion image continues through past, present, and future, repeating itself cyclically, in turn being a whole. Each submission exists in the context of a specific dimension, but it is only as a whole that we see how 
they connect and become one. The second half of the definition of time is backwards because it is on the following page (the back of the transparent page). Words are backwards; to the same effect the layout is untraditional, challenging our understanding of order (see Appendix 11). Time suggests sequence, and even though the content is organized based on past, present, and future, there are overlaps.

The logo on the transparent page frames the written purpose for the creation of Phoenix. This description of the publication provides a foundation for understanding the publication. The description frames and represents the publication in the same way that the logo frames and represents the description (see Appendix 11).

\section{The Exploration of Theory, Content, and Concept Through Formatting:}

Theory and content is communicated to the viewer through the submissions included, from text to images. Additionally, theory and content are communicated to the viewer through the physicality of the publication using different paper, colour, shapes, and through layout and the physicality of the page. The physical creation of the publication embodies connections between theory, content, format, and themes.

The publication features three interviews that were personally conducted: painter Maxime Stein, photographer Lewis Mirrett, and co-founder of Bad Day Magazine, Colin Bergh. Each interview is printed in black and white on coloured paper. Together these three colours, roughly, are a triadic colour scheme. Each colour represents a fragment (a third) of a whole. A triad colour scheme uses colours that are evenly spaced and balanced around the colour wheel. Together they create an equilateral triangle; they are three parts that equal a harmonious colour scheme. Each interviewer's work is displayed in glossy colour. The pairing of black and white text on colour with a coloured image on glossy print speaks to Phoenix being somewhere in the middle of a zine and a mainstream magazine. Printing black and white on colour is a common method of printing in zine production, often used to reduce printing costs. Images in mainstream magazines are often printed in glossy colour. The fusion of both methods reinforces Phoenix as a 
hybrid of both genres of fashion reading (see Appendix 12).

The submission “Competing in a Man's World: The Women's Shoulder Pad of the 1980s" discusses the triangular shape that the shoulder pad denoted for women during this decade and how this shape allowed women to create a new image of feminine identity, particularly in the workplace. It is for this reason that the pages themselves are cut into triangles (see Appendix 13). The triangular format of the paper parallels the triangular shape that the shoulder pad creates on the wearer, which forces the reader to appreciate the untraditional, triangular female silhouette that the shoulder pad created. The untraditional shape of the page also distinguishes Phoenix as an untraditional fashion publication.

The submission titled "Photographs of Photographs" on the 1980s Fashion Advertisements in The Museum of Modern Art include re-photographs of Robert Heinecken's work. Using the method of contact printing, Heinecken used 1980s fashion advertisements, mixing motifs of vanity and consumption (MoMA). These appropriated fashion advertisements are framed and displayed on the walls of The Museum of Modern Art in New York City. This submission explores the method of meta and re-photography. The original photographs were taken for the purpose of advertising beauty products. They originally existed in the pages of a mainstream fashion magazine. Heinecken exposed those images to bright lights, altering the original; his altered photographs of photographs were framed and hung on the walls of The Museum of Modern Art. The originals were for the purpose of advertisements and after being altered by Heinecken were placed in the museum, in a context independent of selling a beauty product.

The photographs in Phoenix are photographs of these framed photographs; the attentive reader can see the reflection of the contributor to Phoenix. In this way, they are photographs of photographs of photographs. These images have been cut out and pasted onto the page in Phoenix where they act as a separate entity apart from its context, like the images themselves in the museum. This meta-method of photography, the format of the pasted image, and the captured 
image of the photographer for Phoenix, highlight in this particular submission the distance in time between the observer and the original image and in general highlight the gap between reality and imagery (see Appendix 14).

Jean Baudrillard in particular wrote about the concept of simulacra. The submission that discusses Baudrillard's “The Precession of Simulacra” is illustrated with two known images: a photograph of model Lindsay Wixon by Terry Richardson and the painting "Red, Orange, Tan, Purple" (1949) by Mark Rothko. In a series these two images morph together, representing an evolution from one extreme to the other. The physicality of the pages, flipping from one page to the next, boosts the effect of the work being a series: an evolution. Where Sontag states a general proposition that the photograph represents a piece of reality (records) and the painting represents an interpretation of reality (interprets), this series of images demonstrates the opposite. By the end of the series, the photograph of Lindsay Wixon is completely transparent (visually and physically), through the use of the transparent page she no longer exists. The photograph of Lindsay Wixon represents a simulacrum. This corresponds with Baudrillard's notion of the simulacra being 'hyperreal' and a negation of the concept of reality. The physicality of the transparent page allows for Baudrillard's theory to be expressed through the formatting of the submission (see Appendix 15). The manner in which images are displayed, from layout to format, connects with the content of the submission and the theory explored throughout Phoenix. The Exploration of Susan Sontag's Theories Through Formatting:

Sontag claims that photography is intimately connected with a discontinuous way of seeing (169). The photograph frames a portion of a whole in the same way that the images and content of Phoenix are merely pieces of a whole perspective on the fashion image. The formatting in Phoenix plays a critical part in defining the fashion image, generally, as a piece or fragment of reality, glimpsed through a window or through a particular lens. Many of Sontag's theories on photography have been explored in the formatting of Phoenix: from the categorization of time dimensions, to the fragmenting of photos, to the cut-up pages and the transparent pages. 
Sontag compares taking photographs with sexual voyeurism (12). In On Photography Sontag uses Diane Arbus' work to explore the politics of photography. Sontag explains that Diane Arbus' love of photography was rooted in the notion of it being a "naughty act" that was "perverse" (13). The similarity between the sexual voyeur and the photographer is that they both encourage whatever is taking place to continue (12). The artistic act is in viewing, not intervening. It is for this reason that the submission in Phoenix on Helmut Newton combines sexuality, voyeurism, and photography. The submission is introduced with a transparent page, printed all in black except for the transparent key hole which acts as a window onto the following page which features one of Helmut Newton's 'Big Nude' photographs. The viewer is the voyeur looking through the keyhole at the nude model (see Appendix 16).

The fashion image in mainstream magazines often relies on mythological romantic depictions with overt hints of sexuality. The bold, full frontally nude Newtonian woman demolishes the romantic character of those images and thereby challenges the mainstream fashion image. The format in Phoenix with the transparent page emphasizes the themes of photography, sexuality, and voyeurism as developed by Sontag and pokes fun at the excess of voyeurism in mainstream magazines.

\section{Mythology}

\section{Appropriation and Simulation:}

The method of appropriation explored throughout this creative project speaks to Jean Baudrillard's concept of simulation. In the "The Precession of Simulacra" Baudrillard claims that society is so saturated with copies (which depict semblances of truth through signs and symbols) that all meaning becomes worthless by being infinitely mutable. Though Baudrillard is not speaking directly to fashion images, this concept nevertheless applies to our image-obsessed world. Sontag has distinguished pictorial from documentary images, but all images are simulacra. The fashion image has the additional aspect of simulacra because it is manipulated, 
reproduced and copied using mythology as a tool to promote false ideals which in turn increase consumption.

Fashion images, when extracted from the consumerism that generates them, have independent value that can be captured through the act of appropriation. Phoenix uses appropriation and détournement to bring light to the falsities of the fashion image, to challenge traditional notions of fashion, and to redefine the use of fashion images. Baudrillard referred to simulacra as having no substance or quality of the original, whereas in every instance of appropriation found in Phoenix, from concept to format and content, the images from the original media are recognizable to the viewer.

Mythology in Relation to Profit-Driven Motives:

Roland Barthes' 'Mythologies' demonstrates how myth is established. When applied to the fashion image, brands, designers, and magazines use signs and symbols to create myths to sell themselves or a product. Mythology is used to impose bourgeoisie norms. In reference to fashion, these bourgeoisie norms might refer to notions of wealth, sexuality, femininity or beauty. Phoenix demonstrates how the fashion image can exist beyond profit-driven motives, and therefore, beyond imposing any bourgeoisie norms. Phoenix is not for profit. Contributors are not paid, and content is not created to sell any product or brand. Phoenix subversively pokes fun at the exclusivity of mainstream fashion. Limited copies are produced, but not for the purpose of distributing. This collection of works does not exist anywhere else; it is an original.

\section{Profit-driven Mythology versus Creative Mythology:}

The consequences of mythology in the fashion image can be explained in relation to Jean Baudrillard's "The Precession of Simulacra." To simulate is to feign to have what one does not have. This threatens the difference between what is true and what is false, what is real and what is imaginary. When the fashion image is studied as a product of profit-driven motives, it is evident how the simulacra can construct false notions of what is true beauty, wealth, femininity, sexuality, or success in the viewer. In this sense, simulacrum is synonymous with mythology. 
Once the commercial motives behind mythology are removed, the danger, or negative consequences of mythology are diminished. When the purpose and context of the fashion image is altered, the effects on the viewer change as well. Phoenix demonstrates different ways, contexts, and media through which to view the fashion image. The fashion images in Phoenix make no attempt at representing 'real' life, but rather can be understood as a form of expression and therefore an interpretation.

Mythology in Phoenix is used in the same way surrealism is used in art: to shock, to express creativity, and to inspire. Some of the content in Phoenix speaks to mythology; some of the content features images that possess myth. The mythology in Phoenix challenges the mythology of mainstream fashion images. The images are not used to create false ideals or to manipulate our notions of truth or reality, but rather as a means of escapism and fantastic revelry. Like myth for ancient Greek philosophy, mythology in fashion is a way to interpret aspects of life. The fashion image is used as a form of expression of creativity and culture, like other art forms, rather than as a tool to create mythical 'documentations' of reality for the purpose of economic gain.

\section{Mythology and the Medium of Photography:}

In On Photography, Sontag provides insight into how mythology develops through the medium of photography. Photography is the primary tool for creating fashion images in today's mainstream magazines. The photograph is a powerful source of meaning since it has historically been used as a way to document reality. Today, particularly with fashion images, the assumption that the photograph represents truth no longer holds true. Tools of manipulation allow the author to alter reality. Mythology can be used to promote false ideals, and in turn alter our understanding of what is true in nature (what is 'real'). Mythology in Phoenix is used solely for the purpose of creative expression, going beyond using myth as a tool of promotion. Several submissions analyze mainstream fashion images to uncover myth and decode such images as interpretations of reality. Additionally, other media are explored as fashion images, for example, 
painting, graphic design, and illustration, demonstrating that the fashion image is not confined to photography.

Fantasy, once limited to painting and illustration, has become an aspect of art more generally,. In mainstream fashion images, fantasy exists in and through photography. Sontag theorizes that the theatricalization of the 'real' is unnecessary and redundant in photography because surrealism lies at the heart of the photographic enterprise (52). The photograph already acts as a creation of a duplicate world (40). That said, Phoenix aims to demonstrate that photography can be used as an artistic medium, like painting, illustration, or writing, to see life through a creative lens.

\section{Authorial Intent in the Fashion Image:}

In the critical essay "The Death of the Author," Roland Barthes claims that knowing the author's intent affects the interpretation of the viewer. Barthes' theory is in relation to written works. When applied to the fashion images of mainstream magazines, his theory proves to be problematic. It is difficult to miss the author's intent in fashion images in mainstream magazines; it is all about selling. Arguably the success of appropriating fashion images may vary as the intent of the authors are mixed. The works of some fashion photographers may make the voyage from origin to destination more easily.

The intent of some of the authors' submissions in Phoenix has been canvassed. They have something to say. Phoenix is a representation of different people's ideas, expressions, and perspectives. Phoenix includes works by women, works on women, and works that speak to women in order to provide a representation of the relationship between women and fashion and the image-making process. In the end, it is the intent of the publication as a whole that is communicated to the reader.

\section{Recurring Triadic Relationship}

There is a recurring triadic relationship that exists throughout this research project. This publication includes a dimension of time. Each submission is categorized into one of the three 
time dimensions: past, present, and future. Though each submission is categorized, the continuity throughout each dimension demonstrates how the content of each dimension flows into the next, in turn becoming cyclical. This serves the purpose of demonstrating the timelessness of fashion, and specifically the fashion image. Each of these photographs is broken up by a transparent page with a third of the Phoenix logo printed on it. Together these three transparent pages equal the whole logo. In a similar way, this demonstrates how three parts equal a whole.

My theoretical framework includes Susan Sontag, Jean Baudrillard and Roland Barthes. Each of these three theorists speaks to mythology. Barthes discusses how myth is established (the creation of myth through signs). Sontag discusses myth in relation to the medium (photography). Baudrillard speaks to the communication of myth in terms of what myth creates (simulacra). This triadic relationship between their works provides a solid foundation for the understanding of mythology, which can then be applied to the fashion image. This relationship is used as a foundation to understand the life of the image. This triadic relationship is expressed through the physicality, format, and layout of Phoenix.

Three specific-methods were used in the creation of Phoenix: corpse exquisite, meta, and détournement. Each of these three methods is a form of appropriation and was used in the content and the formatting of the publication. It is through these methods that we are able to connect theory with format through design. That said, three separate things exist in one act of appropriation: the original, the object/concept/idea appropriated and the new object. Three are also required in a process of meta: a photograph of an image of an image.

There are three interviews. The text of each interview is printed in black and white on coloured paper: red, yellow, and blue. These three colours are equidistant from each other on the colour wheel. Though the coloured paper used are not the exact shades of hues on the colour wheel (not balanced exactly), they roughly create a triadic colour scheme. This colour scheme of primary colours creates a combination that is harmonious and complementary. 
In the submission titled "Competing in a Man's World: The Shoulder Pad of the 1980's," the pages are cut into triangles. Three triangles make up the whole featured image. The number three repeats itself throughout the publication from theory to format to content.

\section{Limitations}

The limitations that arose in the process of creation strengthened the physicality and core concept of Phoenix. When using other people's images there are various copyright laws and issues. Not being able to use other people's photographs ignited the idea to use the method of meta in creation. Some of the photographs featured are photographs that I took of other people's work. The originals are properly cited throughout, even though their originals are not featured.

In creating a publication, software programs like Adobe's InDesign and Photoshop were used. With little technical knowledge or skill of these programs, it was a challenge to self-teach how they function. My limited technical skills offer an original creation. Phoenix does not appear professional and does not resemble the design or layout of the mainstream fashion magazines we are accustomed to viewing. The fact that Phoenix is created by a non-professional, in a nonofficial way adds to the fact that I have appropriated aspects of the traditional fanzine. In a way, it parallels the Japanese aesthetic of 'wabi-sabi,' which represents an aesthetic centered on the approval of imperfection. This 'imperfect aesthetic' speaks to the medium and style of Phoenix, and additionally fits within my intention of going beyond the mythologies found in mainstream fashion magazines that promote false ideals of perfection for profit-driven motives.

There were various limitations in the printing process that guided the end result of Phoenix. It is expensive to print and reproduce multiple copies of a publication. These cost constraints encouraged the creation of a limited-run publication rather than many. This places Phoenix as an art object rather than as a publication created for distribution. Its physicality, from the paper, cut-outs, and format, were prepared by me. Because of limited options offered by the printing company, I was forced to gather the chosen paper (transparent and coloured) and cut the 
pages in the publication myself. These physical alterations and diverse papers collected add to the value of print and Phoenix being an art object created by me.

\section{Areas for Further Development}

Though limitations of time and money restrained me from creating a series of three publications, it encouraged me to focus on Phoenix being a work of appropriation art rather than one in a series of publications. Areas for further development might involve creating two more Phoenix artifacts. The goal in creating two additional artifacts would be to create a trilogy (adding to the thread of multiples of three used in the creation of Phoenix). One possible direction is that each new Phoenix publication appropriates from the previous, with each subsequent publication becoming more specific. The method of meta would be used, taking abstractions of various concepts and content and exploring them more specifically and more in-depth. The size of the following publications would be smaller and smaller. By way of example, this publication is 7 by 10 inches, the following would be 5 by 8 inches and the third 3 by 6 inches. The narrowing down of the size is in line with the themes and topic that are explored, becoming more specific. At the end of the series the two following publications physically fit within the original publication existing today; they are united as one. In turn Phoenix becomes an extensive work of appropriation: object within an object, within an object (fitting into one another) that we can celebrate for their relationship one to the other. 


\section{Chapter 6: CONCLUSION}

This practice-based research project translates theory that speaks to mythology by Susan Sontag, Jean Baudrillard, and Roland Barthes into a work of appropriation art for the purpose of visually and tactilely exploring the relationship between mythology and the fashion image. The relationship between theory, methods, themes, content, layout, and format constantly interacts throughout Phoenix.

The original purpose of this project was to provide a new, alternative medium for the fashion image where it could exist as an expression of creativity and culture, evoking emotion and critical thought, rather than as a tool for profit-driven motives. I gathered content from contributors and my own works, all of which speak to one or more of my themes of interest: cultural communication, the value of print, feminism, and mythology in relation to the fashion image. These themes guided the content of Phoenix.

My intention for this master's research project before the creation of Phoenix was to provide a medium for the fashion image to exist independent of commercial and profit-driven motives. The goal was to showcase alternative fashion images in an alternative context, where the fashion image could be understood as an expression of creativity and culture, evoking emotion and critical thought. While this remains true, through the creation of Phoenix, this project has developed. It has evolved into an in-depth work of appropriation art, an object in and of itself. The project involves numerous layers through the interplay of content, exploration of themes, theory, format, and layout. Every decision made in the creation of Phoenix has been informed by theory, and themes of interest. Where the content informs my themes of interest, theory informs the format. It is through the creation of Phoenix that correlations began to connect in unexpected ways.

The primary result of this collation of images and media is a visual and tactile expression of the theories of Sontag, Baudrillard, and Barthes as it applies to the fashion image. The tangibility of the paper allows for aesthetic effects that speak to theory and content (the cutting of 
pages, the transparency of the paper, and the layout of the pages) informing the relationship between mythology and the fashion image. The secondary result of this research into the interrelationship between scholarly research and creative practice is its contribution to the development of creative research projects, and in particular how research can be conducted in a creative context. The creation of Phoenix is complete. However, it is my hope that the perspective that it endorses will live on, like its content and the paper it has been printed on. The life of the image is infinite and it is for that reason that the symbols and signs of mythology that it possesses should be used to evoke creativity, emotion, and critical thought rather than consumerism and false ideals. 


\title{
APPENDICES
}

Appendix 1: Letter of Consent for Ryerson's Research Ethics Board

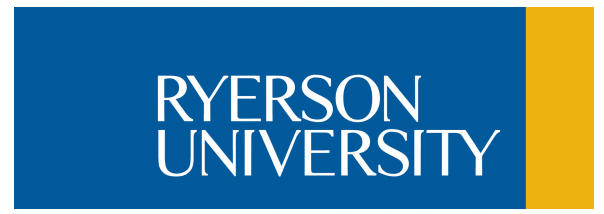

\author{
Phoenix: Rebirth of the Fashion Image \\ Chloe Wilson \\ MA Fashion \\ Consent Form
}

You are being asked to participate in a research study. Before you give your consent to be a volunteer, it is important that you read the following information and ask as many questions as necessary to be sure you understand what you will be asked to do.

\section{Investigators:}

My name is Chloe Wilson. I am a graduate student of Ryerson University's Master of Art Fashion program. I can be reached at chloe.wilson@ryerson.ca.

My supervisor for this project is Professor Joseph Medaglia. He can be reached at jmedaglia@ryerson.ca.

\section{Purpose of the Study:}

This project is designed to demonstrate alternative ways to showcase the fashion image in an unconventional manner through different artistic mediums by different contributors (writers, illustrators, photographers, painters, and graphic designers). It aims to explore the value of print, cultural communication, fashion as an indicator of society, and feminism and fashion. Each submission will contribute to one or more of such themes. My publication Phoenix will provide a medium that will showcase the fashion image as an expression of creativity and culture, independent of commercial and profit-driven motives. The publication itself is not for commercial use, rather for my master's research project.

There are various contributors however only a limited amount of interviews. Full interviews and quotations will be published in the final publication. Participants have the option to review content before it is published.

\section{Description of the Study:}

Interview will take place at a private room in a public library or at an office at Ryerson University, or at another location at the subject's convenience. You will be asked to answer up to fifteen questions. Interviews may be conducted via e-mail once subject reads and accepts the Consent Agreement. In-person interviews will take no longer than 30 minutes. Only one meeting or e-mail exchange is required. Questions will involve your work, how it applies to fashion and your opinions on the following themes (depending on their profession and area of interest): 
-Cultural communication

-The value of print

-Fashion and society

-Mythology of the fashion image

-Feminism and fashion

Your name, a description of your work and the interview will be included in the publication. As previously mentioned, you have the option to review the content before it is published. At your request, the final draft will be sent to you via e-mail prior to publishing,

\section{Risks or Discomfort:}

Interviews will involve questions about your personal and professional opinions regarding one or more themes that this project explores:

-Value of Print

-Feminism and Fashion

-Mythology of the Fashion Image

-Cultural Communication

Interview questions will depend on the participant.

If you find any or all of the questions to cause discomfort, you have the option to skip a question or discontinue participation (either temporarily or permanently). At your request, you have the option to review chosen quotations and full interview before publication.

\section{Benefits of the Study:}

This study will demonstrate how the fashion image can exist beyond commercial and profit-driven motives. It will showcase the fashion image in a new light: devoid of mythology, from a variety of perspectives, using different mediums, celebrating women, fashion, print and culture. The mainstream fashion image is a powerful social force in the construction of representation and identity. This project is valuable because it explores an alternative way to understand the fashion image. Though contributors will not be financially compensated, each contribution and interview will participate in furthering alternative ways of presenting the fashion image. Inclusion in this publication provides the opportunity for your work to be exposed to Ryerson University's academic community: MA Fashion program faculty and students. However, you may not gain any direct benefit from participating in this study.

\section{Confidentiality:}

All interviews will be audio recorded and typed up by myself. Documents and images will be saved to my hard drive for the duration of my project (to be completed end of April 2013). Contributors may review any interview or image before publication and may chose to discontinue participation. Once published, Phoenix will be showcased at the MA Fashion Exhibit in April 2013. Fewer than fifty copies will be made and distributed (for free) to fellow Master's students and Fashion faculty. This project is not for commercial use. Distribution among fellow 
classmates and Ryerson fashion faculty will be done for the purpose of promoting my master's research project. Note, all interviews are used solely for the purpose of Phoenix publication and all recordings of interviews will be secured electronically by both password protection and encryption.

\section{Incentives to Participate:}

As mentioned above I am unable to compensate participants. Inclusion in this publication will present an opportunity for your work and/or opinion to be exposed to Ryerson's academic community. Your opinion and work will contribute to a greater understanding of the fashion image.

\section{Voluntary Nature of Participation:}

Participation in this study is voluntary. Your choice of whether or not to participate will not influence your future relations with Ryerson University. If you decide to participate, you are free to withdraw your consent and stop your participation at any time without penalty or loss of benefits to which you are allowed.

At any point in the study, you may refuse to answer any particular question or stop participation altogether.

\section{Questions about the Study:}

If you have any questions about the research now, please ask. If you have questions later about the research, you may contact.

Chloe Wilson

chloe.wilson@ryerson.ca

If you have any questions regarding your rights as a human subject and participant in this study, you may contact the Ryerson University Research Ethics Board for information.

Research Ethics Board

c/o Office of the Vice President, Research and Innovation

Ryerson University

350 Victoria Street

Toronto, Ontario

M5B2K3

4169795042

Please sign below to indicate that you have read, understood and accept the above consent form.

$\mathrm{X}$

Please sign below to indicate that you are willing to be audio recorded for the interview.

$\mathrm{X}$ 
Appendix 2: List of Contributors:

Chloé Wilson, creator \& editor

Renée Rodenkirchen, photographer and independent filmmaker

Kathryn Macnaughton, illustrator

Danielle Hession, mixed-media artist and graphic designer

Colin Bergh, art director and co-founder of Bad Day Magazine

Maxime Stein, painter

Lewis Mirrett, photographer and artist

Charisse Weston, author

Appendix 3: Phoenix's untraditional size dimension: 7.25 by 10 inches
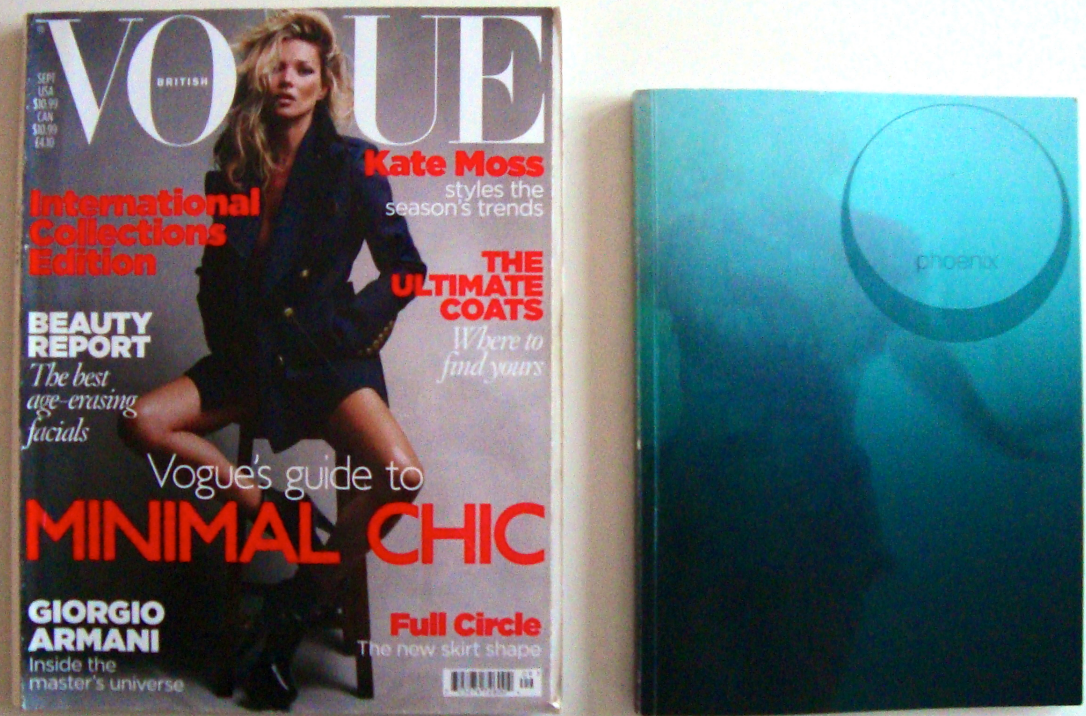
Appendix 4: The method of 'corpse exquisite' in a specific submission

Left image by Renée Rodenkirchen

Right image by Kathryn Macnaughton
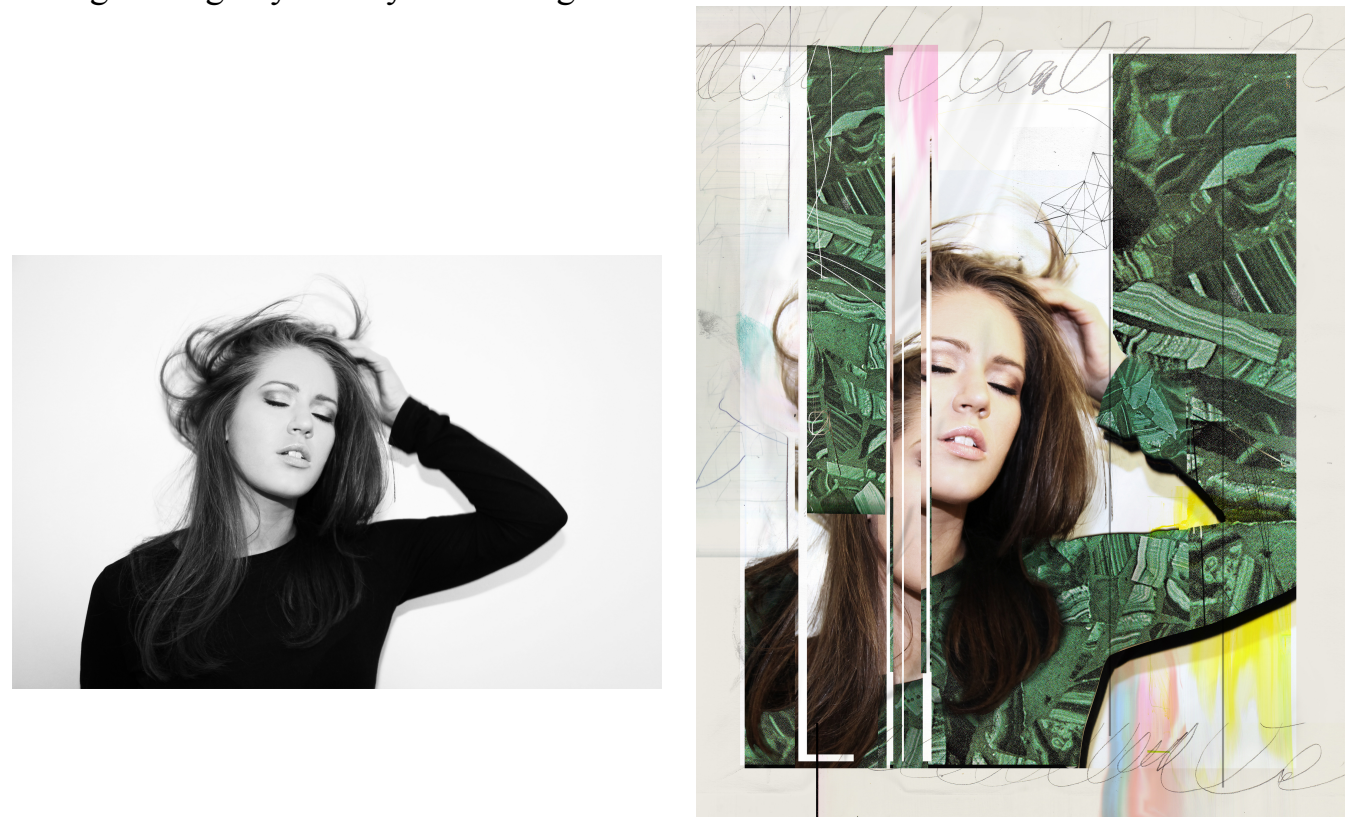

Appendix 5: Appropriation Art by Danielle Hession

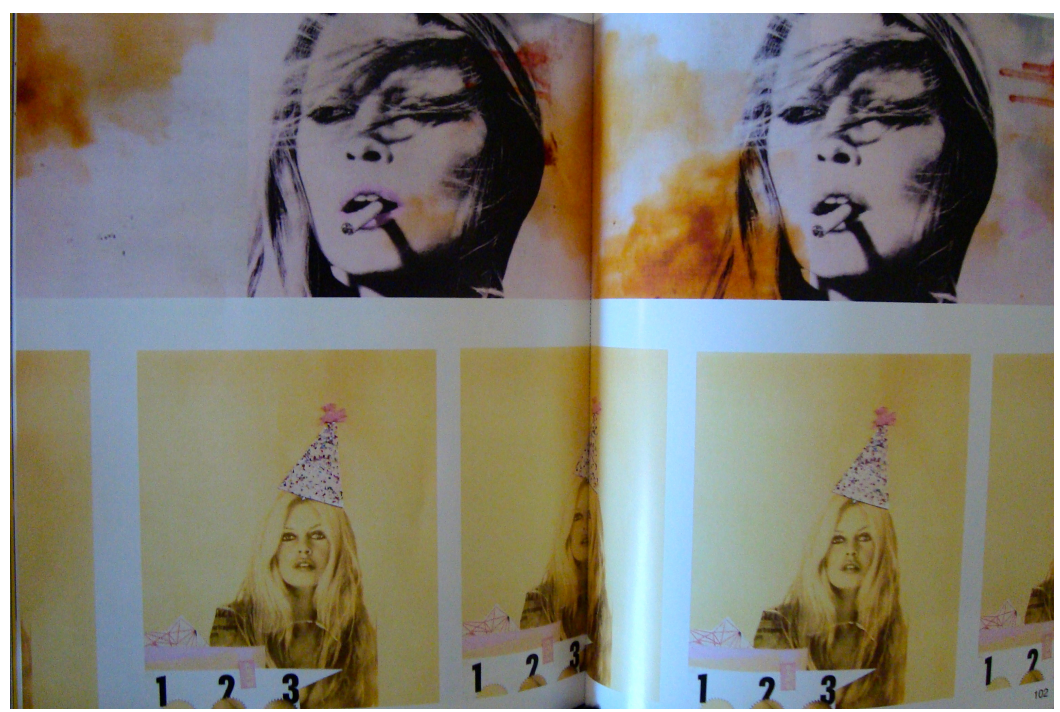


Appendix 6: Phoenix logo

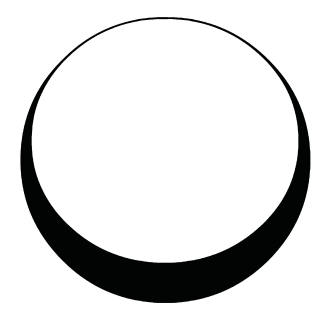

Appendix 7: The representation of a full stroke: cover image, introductory image, and concluding image

Introduction page: swimmer diving into the publication

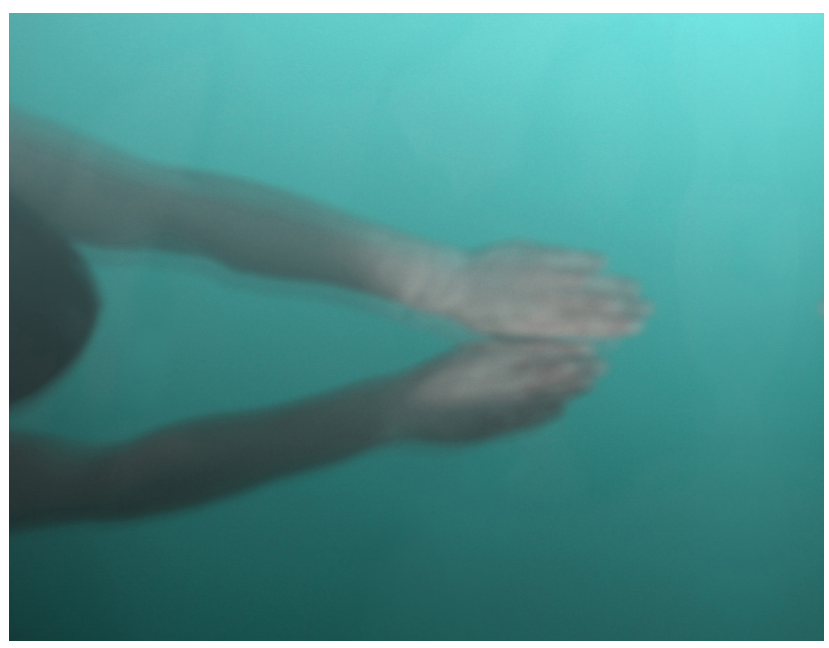

Concluding page: swimmer swimming out of the publication 
Cover image: Swimmer doing a full stroke

Appendix 8: Transitory photographs by Nicolas Wilson

Past

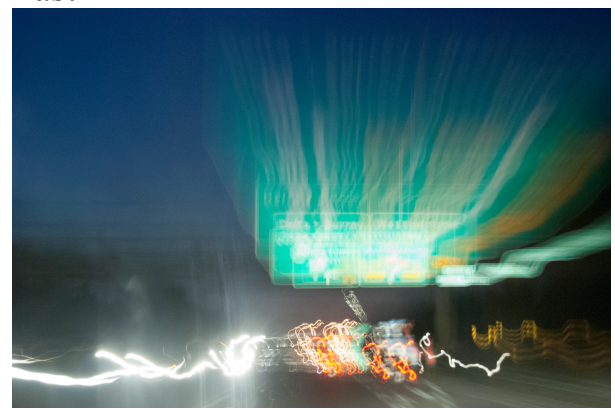

Future

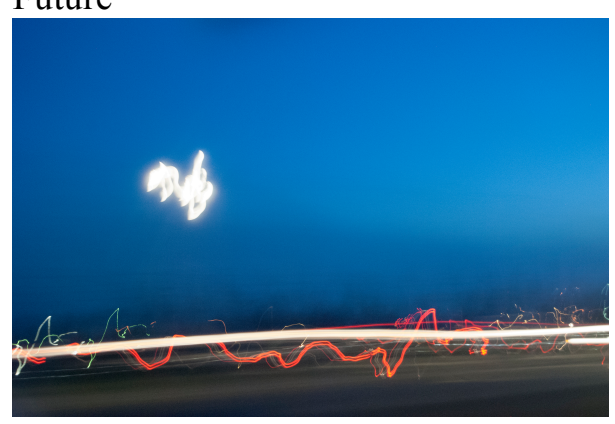

Present

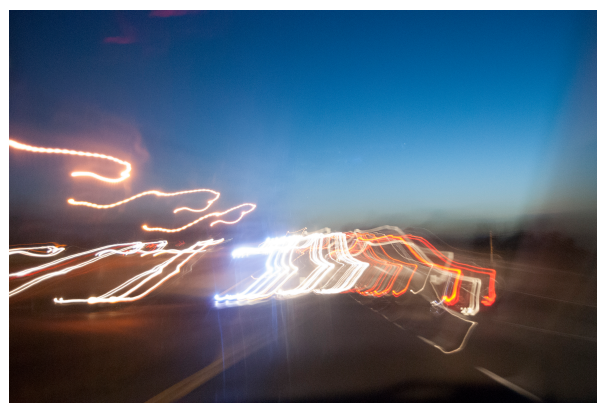


Appendix 9: Transparent Pages for Time Dimensions

Past Time Dimension
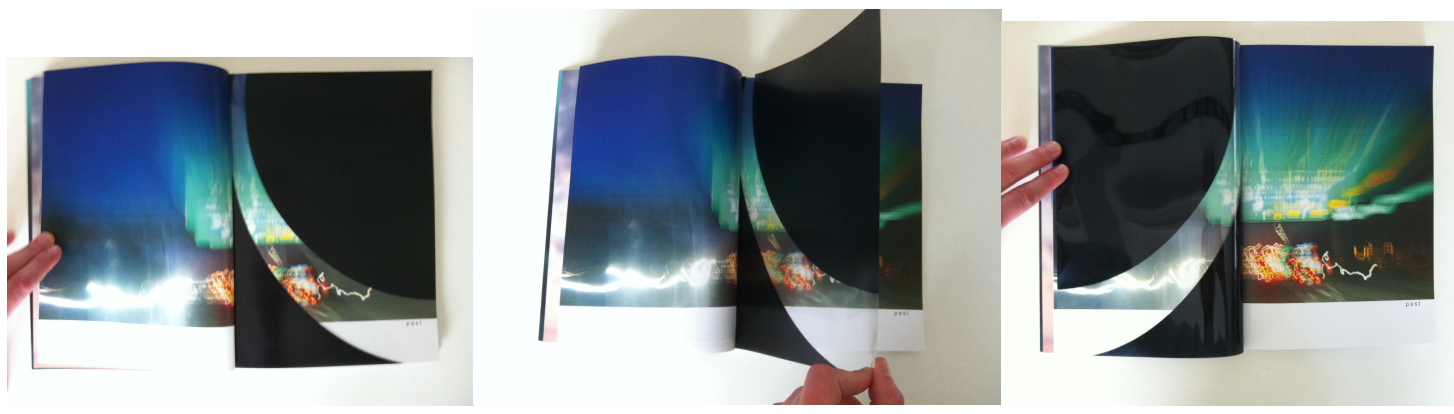

Present Time Dimension
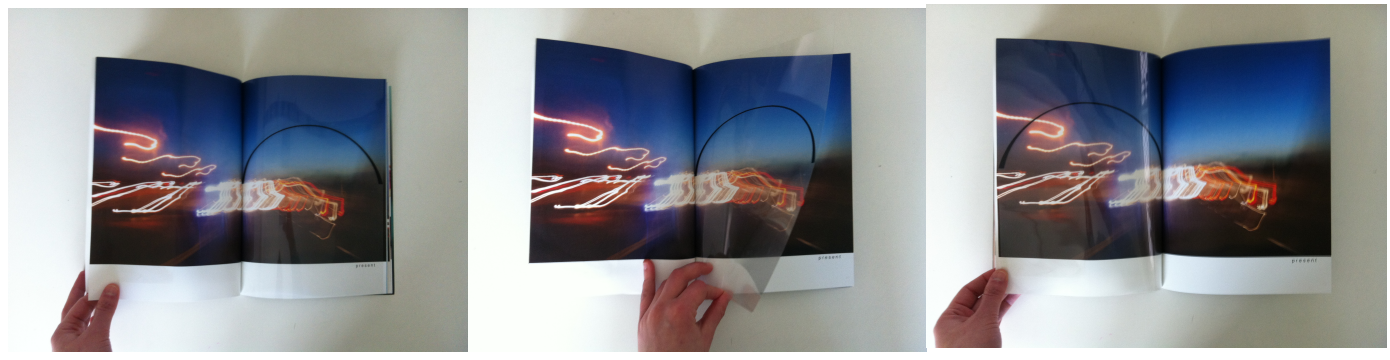

Future Time Dimension
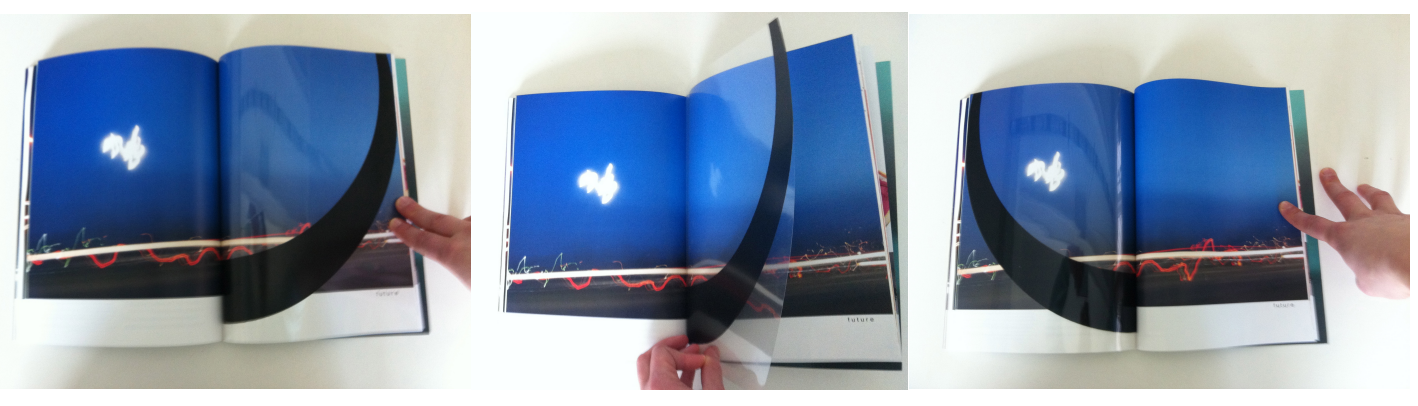
Appendix 10: Last page of Phoenix, demonstrating the contents of past, present and future sections as a whole

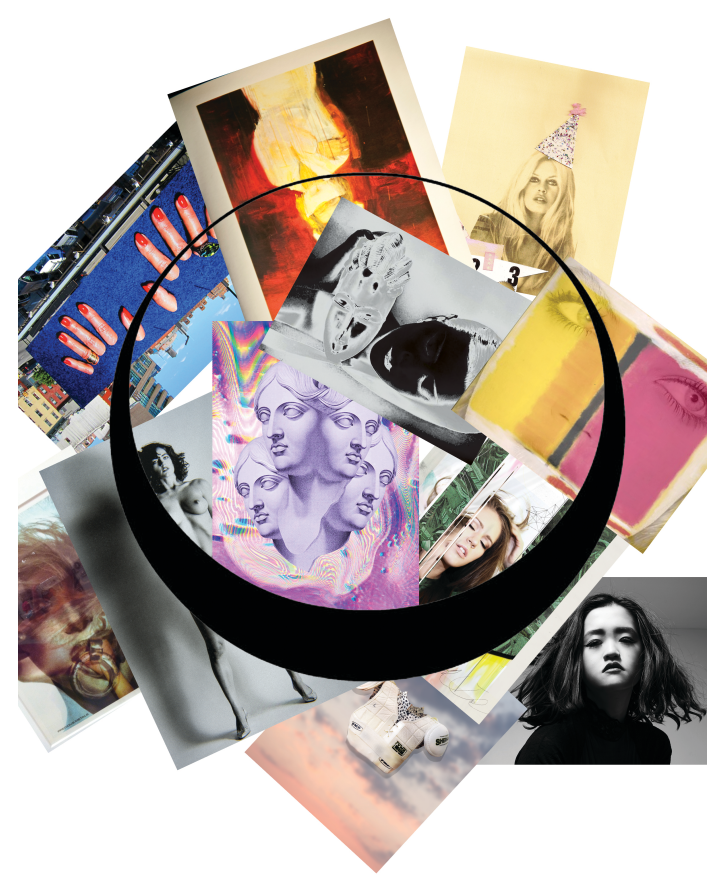

Appendix 11: Introduction to Time
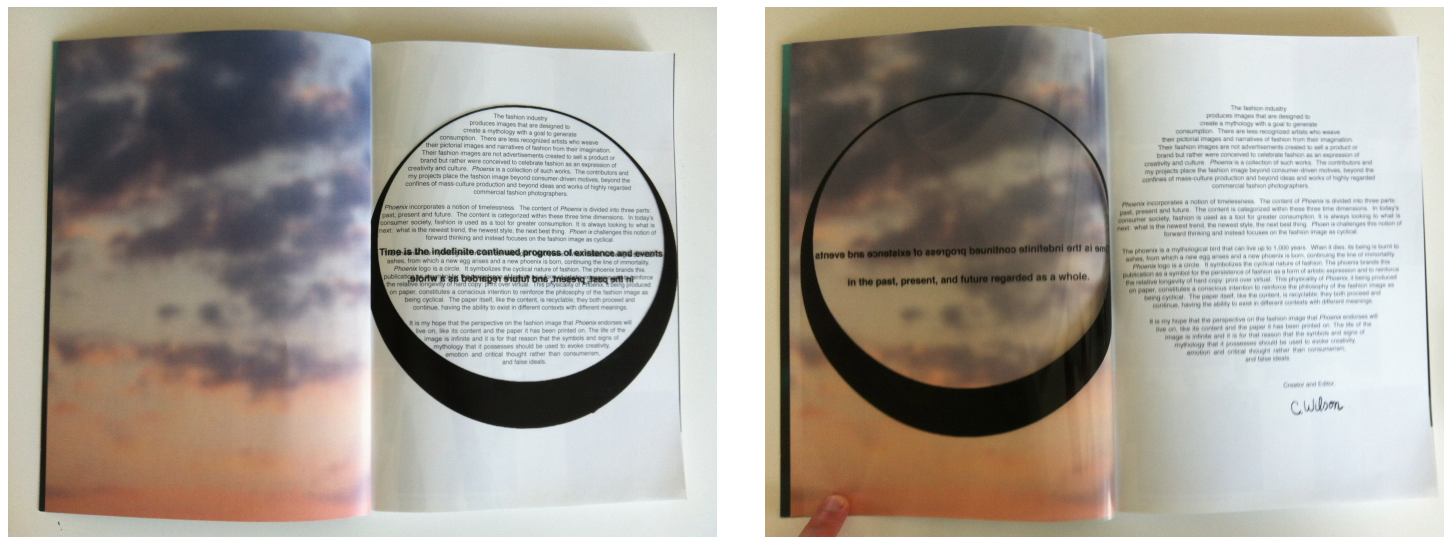
Appendix 12: Interviews printed in black and white on uncoated colour paper (red, yellow and blue), combined with featured images printed in colour on coated glossy paper.
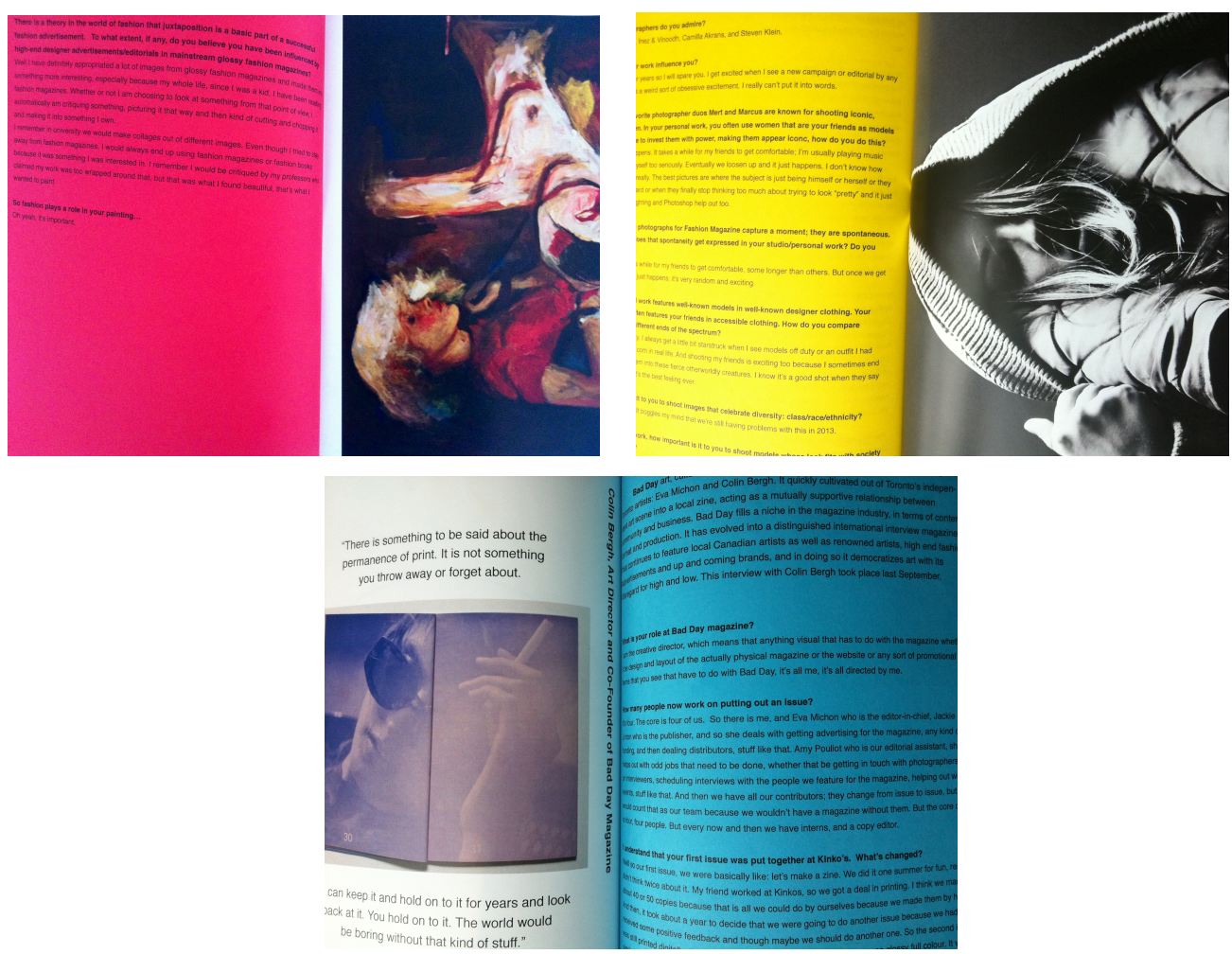

Appendix 13: Formatting of "Competing in a Man's World: The Women's Shoulder Pad of the 1980 s". Pages are cut by hand into triangles to represent the triangular shape explored in the content of the submission.
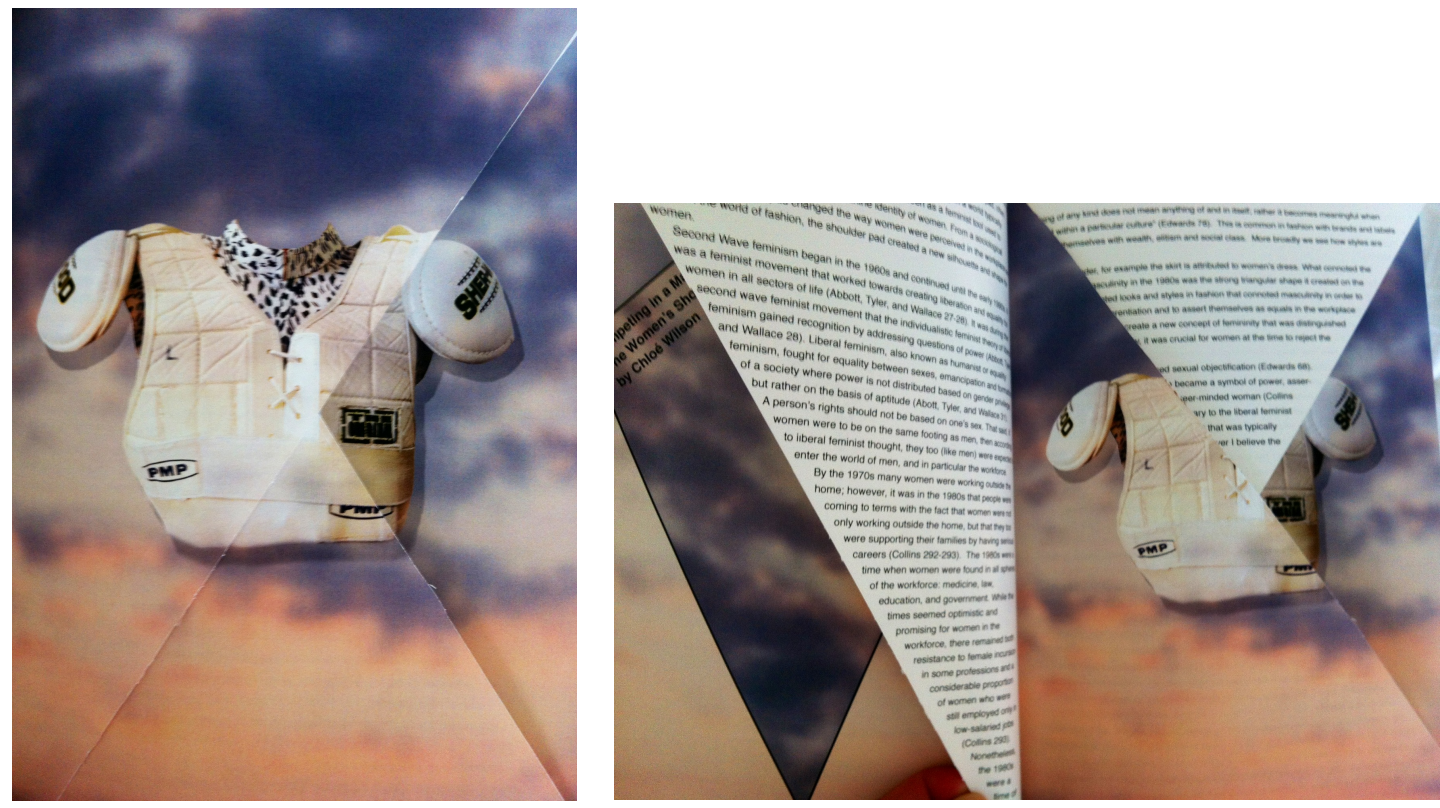
Appendix 14: The method of 'meta' explored in the image-making process and format of the submission "Photographs of Photographs: 1980s Fashion Advertisements in the Museum"

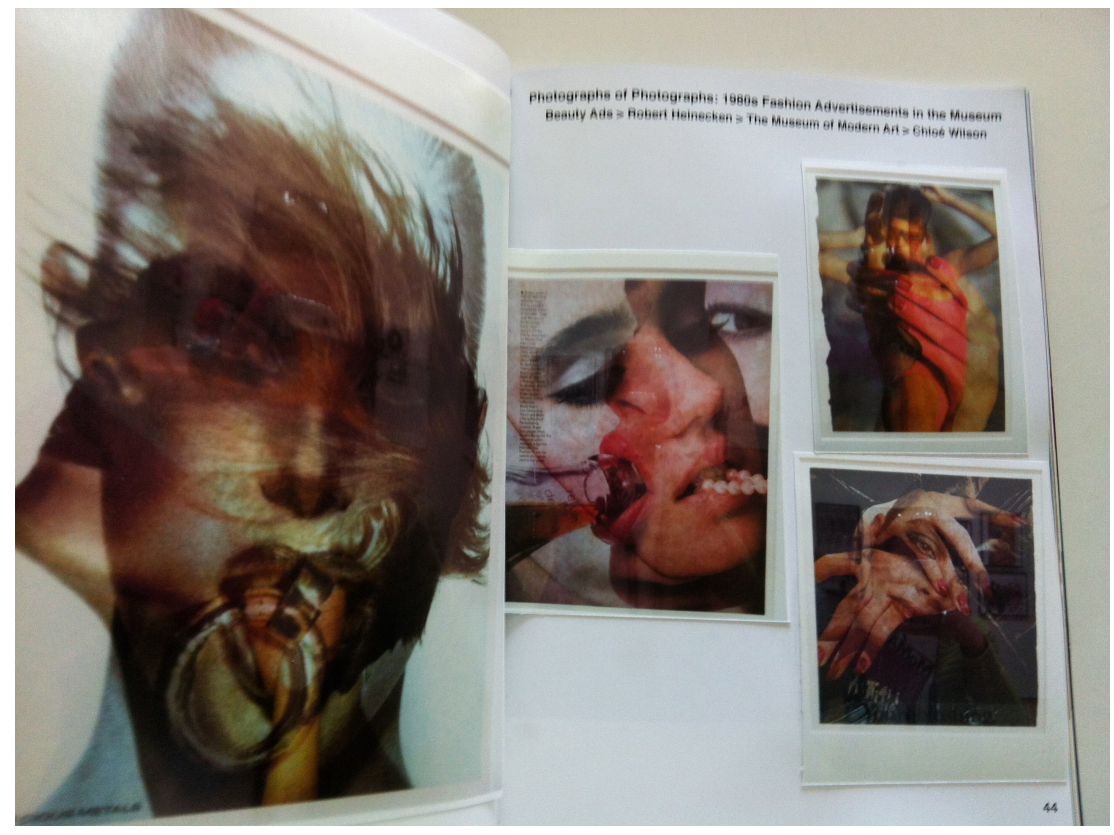

Appendix 15: Formatting of submission on "The Precession of Simulacra"
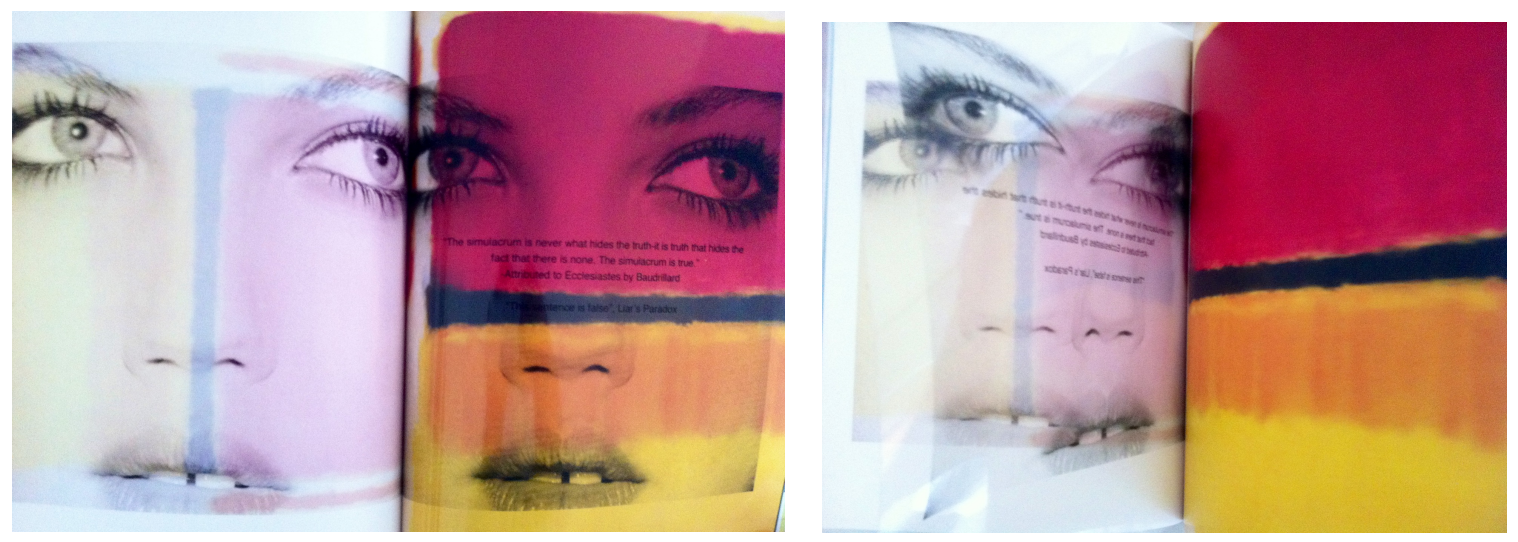
Appendix 16: Voyeurism explored through the formatting of "The Power of the Fashion Image: Helmut Newton and the Female Gender Identity of the 1980s
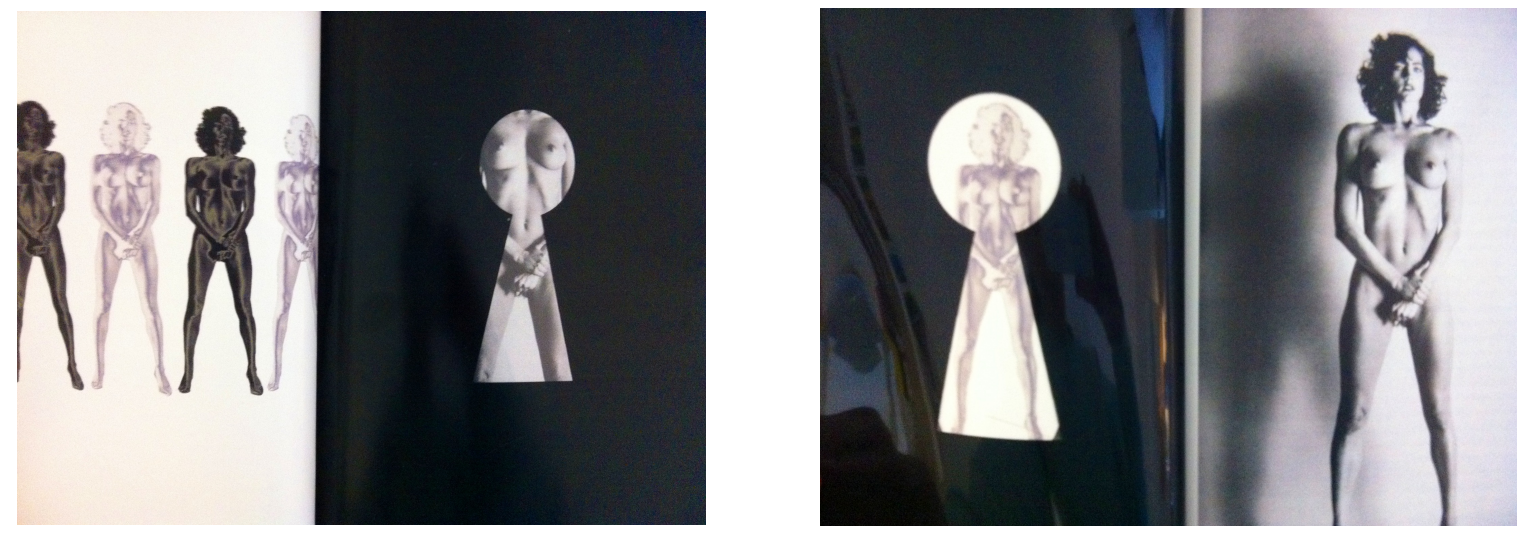


\section{WORKS CITED}

Allen, Gwen, and Cherise Smith. "Publishing art: Alternative distribution in print." Art Journal, 66.1 (2007): 41-45. Web.

Aziz, Tahara. "Shifting the Frame: From Critical Reflective Arts Practice to Practice Based Research.” Journal of Media Practice. 10.1 (2009): 69-81. Web

Barthes, Roland. "The Death of the Author." Art and Interpretation: An Anthology of Readings in Aesthetics and the Philosophy of Art. Ed. Eric Dayton. Peterborough, Ont.: Broadview, 1998. 383-386. Print.

Barthes, Roland. The Fashion System. California: California University Press, 1983. Print.

Barthes, Roland. Mythologies. New York: Hill and Wang, 1957. Print.

Baudrillard, Jean. "The Precession of Simulacra". Media and Cultural Studies. Ed. Meenakshi Gigi

Durham and Douglas M. Kellner. Malden, MA: Blackwell, 2006. 453-481. Print.

Brookes, Rosetta. "The Double-Page Spread: Helmut Newton, Guy Bourdin \& Deborah Turbeville." Fashion Theory: A Reader. Ed. Malcolm Barnard. New York: Routledge, 2007. 517-519. Print.

Chiang, I-Ping, and Chung-Hsien Hsien. "Exploring the Impacts of Blog Marketing on Consumers." Social Behavior \& Personality: An International Journal, 39.9 (2011): 1245-1250. Web.

Craik, Jennifer. The Face of Fashion. London: Routledge, 1994. Print.

Crane, Diana. "Diffusion Models and Fashion: A Reassessment." The Annals of the American Academy of Political and Social Science, 566 (1999): 13-24. Web.

De Perthius, Karen. "The Synthetic Ideal: The Fashion Model and Photographic Manipulation." Fashion Theory 9.4 (2005): 407-424. Web.

Dijck, José Van."Digital photography: Communication, Identity, Memory." Visual Communication, 7.1 (2008): 57-76. Web.

Goldberg, Greg. "Rethinking the Public/Virtual Sphere: The problem with participation." New Media \& Society, 13.5 (2011): 739-754. Web.

Hebdige, Dick. Subculture: The Meaning of Style. London: Methuen \& Co. Ltd, 1979. Print.

Hebdige, Dick. Hiding In The Light. London: Routledge, 1988. Print.

Maarit, Makela. "Knowing Through Making: The Role of the Artifact in Practice led Research." Knowledge, Technology \& Policy. 20.3 (2007): 157-163. Web. 
Manlow, Veronica. "Creating an American Mythology: A Comparison of Branding Strategies in Three Fashion Firms". Fashion Practice: The Journal of Design, Creative Process \& the Fashion Industry, 3.1 (2011): 85-110. Web.

McCraken, Ellen. Decoding Women's Magazines. New York: St. Martin's Press, 1993. Print.

McRobbie, Angela. Feminism and Youth Culture. New York: Routledge, 2000. Print.

McRobbie, Angela. "Post-feminism and Popular Culture." Feminist Media Studies 4.3 (2004): 255-64. Web.

McRobbie, Angela. The Aftermath of Feminism: gender, culture and social change. London: Sage, 2009. Print.

McRobbie, Angela. Postmodernism and Popular Culture. New York: Routledge, 1994. Print.

"Meta.” Def. 2 and 3. The New Oxford Dictionary of English. $1^{\text {st }}$ ed. 1998. Print.

Moeran, Brian. "More Than Just a Fashion Magazine." Current Sociology, 54.5 (2006): 725-744. Web.

Negus, Keith, and Michael Pickering. Creativity, Communication and Cultural Value. London, England: Sage Publications Ltd, 2004. Print.

Paulus, Paul B., and Bernard Arjan Nijstad. Group Creativity : Innovation Through Collaboration. [N.p.]: Oxford University Press, 2003. eBook Collection (EBSCOhost). Web.

Schroeder, Jonathan."The Artist and the Brand." European Journal of Marketing, 39.11 (2005): 1291-1305. Web.

Shawcross, Nancy M.. Roland Barthes on Photography. Florida: The University Press of Florida, 1997. Print.

Sontag, Susan. On Photography. United States of America: Sixth Printing, 1978. Print.

Soussloff, Catherine, William Tronzo and Patricia Rubin. "The Aesthetics of Publishing: the art book as object from print to digital." Visual Resources, 24.1 (2008): 39-58. Web.

Wark, McKenzie. "Détournement.” Journal of Theoretical Humanities, 14.1 (2009): 145-153. Web.

Ytre-Arne, Brita.“I Want to Hold it in My Hands': readers' experiences of the phenomenological differences between women's magazines online and in print." Media, Culture \& Society, 33.3 (2011): 467-477. Web. 